2017-01-01

\title{
Optimal Combined Long-Term Facility Design and Short-Term Operational Strategy for CHP Capacity Investments
}

\author{
Jose Mojica \\ Brigham Young University \\ Damon Petersen \\ Brigham Young University \\ Brigham Hansen \\ Brigham Young University \\ Kody Powell \\ University of Utah \\ John Hedengren \\ Brigham Young University, john.hedengren@byu.edu \\ Follow this and additional works at: https://scholarsarchive.byu.edu/facpub \\ Part of the Chemical Engineering Commons
}

\section{Original Publication Citation}

Mojica, Jose L., et al. "Optimal combined long-term facility design and short-term operational strategy for CHP capacity investments." Energy 118 (2017): 97-115.

\section{BYU ScholarsArchive Citation}

Mojica, Jose; Petersen, Damon; Hansen, Brigham; Powell, Kody; and Hedengren, John, "Optimal Combined Long-Term Facility Design and Short-Term Operational Strategy for CHP Capacity Investments" (2017). Faculty Publications. 1906.

https://scholarsarchive.byu.edu/facpub/1906

This Peer-Reviewed Article is brought to you for free and open access by BYU ScholarsArchive. It has been accepted for inclusion in Faculty Publications by an authorized administrator of BYU ScholarsArchive. For more information, please contact ellen_amatangelo@byu.edu. 


\title{
Optimal Combined Long-Term Facility Design and Short-Term Operational Strategy for CHP Capacity Investments
}

\author{
Jose L. Mojica ${ }^{\mathrm{a}}$, Damon Petersen ${ }^{\mathrm{a}}$, Brigham Hansen ${ }^{\mathrm{a}}$, Kody M. Powell ${ }^{\mathrm{b}}$, John \\ D. Hedengren ${ }^{a, *}$ \\ ${ }^{a}$ Department of Chemical Engineering, 350 CB, Brigham Young University, Provo, UT \\ 84602, USA \\ ${ }^{b}$ Department of Chemical Engineering, University of Utah, 50 S. Central Campus Dr., Rm \\ 3290 MEB, Salt Lake City, UT 84112-9203, USA
}

\begin{abstract}
This work presents a detailed case study for the optimization of the expansion of a district energy system evaluating the investment decision timing, type of capacity expansion, and fine-scale operational modes. The study develops an optimization framework to find the investment schedule over 30 years with options of investing in traditional heating sources (boilers) or a next-generation combined heat and power (CHP) plant that provides heat and electricity. In district energy systems, the selected capacity and type of system is dependent on demand-side requirements, energy prices, and environmental costs. This work formulates capacity planning over a time horizon as a dynamic optimal control problem considering both operational modes and capital investment decisions. The initial plant is modified by the dynamic optimization throughout the 30 years to maximize profitability. The combined optimal controller and capital investment planner solves a large scale mixed integer nonlinear programming problem to provide the timing and size of the capacity investment (30 year outlook) and also guidance on the mode of operation (1 hour time intervals). The optimizer meets optimal economic, environmental, and regulatory constraints with the suggested design and operational guidance with daily cyclical load following of heat and electricity demand.
\end{abstract}

Keywords: Combined heat and power, Dynamic optimization, Optimal design, Optimal control, Combined scheduling and control

\footnotetext{
*Corresponding author. Tel.: +1 801477 7341, Fax: +1 8014220151

Email addresses: jlmojica@gmail.com (Jose L. Mojica), damon.j.petersen@byu.edu (Damon Petersen), brighamhansen@gmail.com (Brigham Hansen), kody. powell@utah.edu (Kody M. Powell), john.hedengren@byu.edu (John D. Hedengren)
} 


\section{Introduction}

2

Energy producers and end-users face many challenges as they balance energy demand, economic uncertainty, and environmental regulations. Both private

4 and public utility companies are often pressured into making investment decisions due to the economic and energy demand variability in the presence of in6 creasing environmental regulation 1, 2, Sometimes these sub-optimal decisions include delayed investments which can result in losses in long-term economic benefits. Combined heat and power (CHP) plants, or cogeneration plants, provide an efficient method to balance the multiple energy requirements [3, 4, 5.

10 CHP plants accomplish this feat by simultaneously providing heat and generating power through a single fuel source [6]

While considering CHP implementation, stakeholders must consider expanding traditional combustion units, pollution reduction equipment [7, 8, 9, inclu-

14 sion of renewable generation [10, 11, electricity-only systems, energy storage [12, and constructing new CHP units entirely [2. When these options are

16 coupled with daily dynamics such as demand, fuel cost, and uncertainties such as regulation and price, a dynamic optimization approach which can account 18 for short-term operational scenarios as well as long-term capacity planning is one possible method to deliver improved solutions for the problem. This work 20 presents a precise case study demonstrating the use of such an approach to deliver an improved solution. Much research has been done to effectively account

22 for both short-term operation and long-term strategy [13, 14, 15, 16, 17, 18, 19, 20, 21]. The model in this work provides a long-term planning horizon for a

24 CHP plant in a district energy system that uses constrained differential equations to describe capacity investments over the horizon. This long-term model is 26 coupled with an hourly dynamic optimization approach to provide methodology that considers short term operational constraints as well as long-term investment $28 \quad$ strategy that is optimized simultaneously alongside demand and price forecasts. This formulation solves as a single-cycle of model-predictive control considering 30 a 30 year horizon as well as hourly operations.

\section{District Energy Systems} ing, and cooling to surrounding areas from a central location 22, 23, 24, 25.

34 These systems often include energy storage [26, 27. or shifts in production to accommodate for changing energy demands 28,29 . The energy demand, system constraints, and system dynamics of the given energy network determines the overall effectiveness of the plant. A CHP system is identified by the type 3 of equipment, or prime mover, that drives the overall process. Combustion gas turbines, steam turbines, reciprocating engines, and fuel cells all represent 40 various CHP prime movers that use a variety of fuel sources 3 .

CHP systems with combustion turbine generators (CTG) are popular prime 42 movers for systems requiring more than $1 \mathrm{MW}$ electric load. CTG systems employ a compressor, combustor, and turbine to supply electric loads from 1 
${ }_{44}$ MW to $100 \mathrm{MW}$ [3. Leftover energy from the CTG hot exhaust gas is used to create necessary hot water or steam from a heat recovery boiler, instead of

46 using separate utilities as the heat source. Supplemental burners and boilers are used if extra heating is needed to meet the system heating requirements.

48 Separate heat and power generation systems have relatively low overall efficiency of about $49 \%$ 6. Whereas, the heat recovery portion of a CTG CHP system 50 has about $80 \%$ efficiency, giving the CHP an overall efficiency of about $75 \%$ [30]. District energy systems yield more optimization opportunities by simultaneously

52 providing for electrical, heating, and cooling demands [28, 31]. However, the new demands and constraints of these systems offer more complex problems

54 and require a more diverse range of system models. Optimization methods have been used to increase energy savings and reduce costs, but similar methods 56 have yet to be applied to a district energy system for simultaneous capacity planning and dynamic capacity utilization. This work demonstrates the use of

${ }_{58}$ a formulation that simultaneously accounts for long-term capacity planning and hourly capacity utilization.

60 3. Optimization of District Energy Systems

The design capacity of a power generation system is the maximum produced 62 energy per unit time [32. Energy generation systems tend to be oversized over typical load scenarios because enough adequate energy must be generated when

${ }_{64}$ unusual peak demand episodes occur. Meanwhile, in most cases, thermal energy cannot be imported from an outside source as easily as electricity is imported 66 from the power grid. This forces district energy systems with heating loads to provide dispatchable capacity to meet thermal demands. The design capacity

68 of an energy system can be fulfilled with a single large capacity unit or multiple smaller capacity units, which can be staged on or off as demand changes.

70 Growing energy demands and regulations on existing energy production fleets require that new investments in design capacity be considered. At the same

72 time, energy demand is uncertain because of weather and economic factors. Capacity expansion projects are mostly considered irreversible investments because

74 of high capital cost while the plants remain available for an extended period of time. An aging fleet of coal and natural gas burning boilers provides motivation 76 to plan for new prime movers in district energy systems.

Lozano et al. 33 reports that traditionally there are two main approaches to the design capacity and integration of an energy system: 1) a deterministic thermodynamic approach and 2) a mathematical programming approach. A deterministic thermodynamic approach takes advantage of the physical equations that govern the thermodynamics of the system. This approach solves the equa-

82 tions based on energy demands and design equations of the system components, such as boilers, heat exchangers, evaporators, etc. Pinch analysis methods, also

84 known as heat integration or process integration, are used to find the most efficient configuration of a prescribed energy system based on thermodynamic 86 approaches 34. A pinch analysis approach is often applied to optimize energy consumption when designing chemical or energy generation processes. Instead 
of providing heating and cooling utilities, energy consumption can be reduced by calculating thermodynamically feasible energy targets because energy targets o are absolute thermodynamic values [35].

Mathematical programming has been used extensively for decades to optimize and plan complex systems in many different areas, including energy systems. The mathematical programming approach to design and integration of 94 energy systems uses optimization algorithms to search for a feasible design according to specified criteria [36. If the aim is to minimize cost and plan for

96 optimum capacity of a district energy system, the program must calculate cost and represent the capacity with mathematical equations of the energy output of 98 the system. The economic and mathematical representation of the dynamics and physical system can be done through first principles or empirical (data-driven) models or a mixture of both (hybrid, or semi-empirical) models.

Reviews in the design and planning of complex energy generation systems by Chicco 37] and Mancarella 38 detail mathematical programming formulations used in the literature to solve optimal energy capacity and planning problems. The mathematical formulations included linear programming, genetic and evolutionary algorithms [39, branch and bound for discrete formulations, Pareto 106 optimizations, and Lagrangian-based algorithms. The survey also indicates that problems are typically solved either by looking at short-term or long-term time 108 frames in the optimization time horizon. This separation between long-term and short-term time horizon in the optimization formulation illustrates that a 110 multi-time scale, also known as multi-stage, optimization approach framework is yet to be fully developed, thus providing greater motivation for the value of the optimization framework utilized in this work.

Within the mathematical programming approaches, mixed integer programming (MIP) 40, mixed integer linear programming (MILP) [33, 41, 42, 43, 44, or mixed integer nonlinear programming (MINLP) methods [45] are used extensively in the literature for deterministic optimal capacity and configuration of energy systems. Enterprise-wide dynamic optimization seeks similar objec118 tives but with the use of large-scale nonlinear programming (NLP) solvers [46]. P. Arcuri et al. 41 present an approach that separates the short-term (annual 120 year) versus the long-term (lifetime) use of the energy system. The optimal solution is then derived through an iterative scheme, which allows for the optimal 122 size and configuration of the system that maximizes operational margins over the operational lifetime. Du et al. 13] present a method to bridge time scales 124 for moderate-term (scheduling) and short-term (control) decisions. Combining scheduling and control is an active area of focus with several recent contribu26 tions [14, 15, 16, 17, 18, 19. Contributions by Ricardez-Sandoval 47] and Kim et. al [4] have developed frameworks to simultaneously design and control ${ }_{128}$ large-scale systems under process parameter uncertainty through a sequential method of simulations of the dynamic control problem and the subsequent non-

130 linear optimization of the steady state first principles model. An optimal design of the system is found after iterations of perturbation of the control simulation 132 and the subsequent optimization of the system model to update the dynamic control parameters. Such an approach provides a framework for optimal system 
design that can satisfy both steady state and transient operations. Long term uncertainty in costs or demand forecast for the system are omitted, thus leaving a system that can be economically attractive within the short term dynamic horizon, but economically infeasible in the lifetime of the system when economic and demand conditions may change drastically.

It is evident from the examples above that researchers have attempted to resolve the long-term and short-term challenges of optimal equipment configuration and energy system capacity. This work demonstrates the use of a method to simultaneously optimize a system with short term (1 hour operational intervals) dynamic objectives and long term (30 year planning period) economic and demand forecasts through an optimal control framework. This method is demonstrated in a precise case study of capacity expansion for a CHP facility over a 30-year horizon.

\section{Long-term Capacity Investment Planning}

Decision making involves consideration of multiple objectives and uncertain outcomes; and in many situations, decisions must be made at different times and at different levels. These types of problems are generally referred to as multi-objective decision processes under uncertainty [49]. Planning for capacity and configuration upgrades is important because stakeholders must balance the opposite objectives of economic viability, security of supply, and environmental regulations over time horizons spanning decades. In the utility power generation sector, the objective of generation planning is to determine the number of units, the timing of the investment, and the capacity of the overall system, all while minimizing fixed and production costs [50. The same challenges are faced by district energy systems when expansion or retrofits to more efficient options, such as CHP, are contemplated.

The long-term energy system expansion planning problem is a highly nonlinear discrete dynamic problem [50. In past decades the majority of the methods to solve problems dealing with power generation planning have been related to stochastic mathematical programming [51]. These stochastic methods include dynamic programming, multi-stage stochastic programming (MSSP), and stochastic optimal control [1, 52, 53, 54. The stochastic programming methods have the advantage of explicitly incorporating the probabilistic nature of the problem into the optimization algorithm. The disadvantages include linearization of the problem, which is then solved through linear programming, and simplifications to the probabilistic trees that account for the uncertainty [50. Without simplification, stochastic programming methods suffer from the curse of dimensionality, which makes the problem intractable in finding a solution [49, 50, 55]. The absence of the nonlinear fidelity and dynamics of the problem may increase the difficulty of finding an optimal solution that will have the resolution to fulfill the short term (hourly energy consumption) and long term (capacity and profitability) requirements of the capacity planning problem. Fuss et al. [55] used a real options valuation approach to find a solution in other 
similar problems of investment and planning for power generation systems under uncertainty. They reported that a stochastic programming approach would have resulted in the same outcomes as those obtained in a real options approach. Their work also reports that the main reason for not using stochastic methods was the increased computational intensity due to the dimensionality increase when there are many periods and scenarios as well as a modest state space.

Other less common, but reported, methods in the literature that account for uncertainty in power generation systems expansion and investment planning include fuzzy logic [56] and Monte Carlo simulations [57. Others have used

186 a combination of methods to account for uncertainty [12]. For example, joint probabilistic programming and fuzzy possibility programming are used by Liu ${ }_{188}$ et al. 51 in an optimization approach for power generation planning under uncertainty in a mixed integer linear programming (MILP) framework. Another combined method to account for uncertainty is to use an MSSP and fuzzy linear programming in an MILP framework [58. The benefits of such formulations is in describing uncertainties in terms of interval values, fuzzy sets, and probability distributions. In energy system planning under uncertainty, the combined method approach can reflect dynamic decisions for facility-capacity expansions and energy supply over a multistage context 58 .

Multistage approaches refer to mathematical models that integrate spatial and temporal dimensions, or two or more temporal dimensions with signifi-

198 cantly different scales [59. In planning and scheduling problems 60, the handling of multiple time scales is mostly handled through simplification of the asynchronous time scales to a single representative scale or the separation of the problem into discrete periods. Such simplifications mask the short term response of the system and shift the optimization towards systems that overestimate capacity and favor long term inputs.

\section{Dynamic Optimization for Energy Systems}

Dynamic optimization constitutes a methodology to optimize systems represented by dynamic models in the form of differential and algebraic equations (DAE). The optimization algorithms for dynamic optimization may have non. Dynamic optimization is an integral part of some advanced control algorithms such as Model Predictive Control (MPC). MPC is an accepted advanced control technique that utilizes deterministic process models to predict future responses of a system [61]. The process models used in MPC are sometimes dynamic and nonlinear and capture the dynamic and static interactions between inputs, outputs, and disturbances affecting the system 62. In control applications of complex chemical and energy processes, MPC technology is well utilized because 216 the algorithms not only attempt to optimize the present optimal control moves, but also optimize future system behavior by computing a sequence of future 218 decision variables adjustments 61]. The ability of MPC to predict future variable moves through optimization has similarities to the objectives of capacity 220 planning over a future horizon where economic, environmental, and operational 
targets must be achieved while the capacity of the system must be optimally

planned out under the constraints and uncertainty of the system.

Ricardez-Sandoval et al. 63] reviewed different approaches to integrate optimal process design and control of large systems under process parameter uncertainty. Large systems such as chemical plants are usually designed based on steady state economic calculations, while the control aspects are studied independently. The sequential fashion of the approach from design and control gives rise to unforeseen constraints and limitations that can hinder the economic operation of the system once online. The simultaneous optimization of dynamic control variables and design variables can thus greatly reduce the effect of under-sizing or over-sizing the capacity of the system and improve profitable operation under different market conditions 63. From an uncertainty point of view, the dynamic behavior of system parameters and variables is a factor that must be addressed in power systems optimization 64. This work does not detail the instantaneous process dynamics of the energy system because a longer term multi-decade time scale dominates the process dynamic effects. However, one-hour energy responses are simulated through simple first order differential equations which are explained further in this work. The motivation to include one-hour system changes to optimize capacity planning of energy systems comes from practical experience reported in previously planned and constructed plants in which owners find that the planned capacity is not fully utilized, is insufficient, or is no longer cost effective given changing economic conditions and the load following system requirements 65. This work also demonstrates the use of novel methods for using soft constraints to integrate various control scenarios into the capacity planning optimization problem to further reduce the possibilities of the aforementioned problems of insufficient capacity, loss of cost effectiveness, and sub-optimal utilization.

\section{Nonlinear Dynamic Modeling}

A general model form for a nonlinear dynamic problem can be formulated as follows

$$
\begin{gathered}
\min J(x, y, p, d, u) \\
0=f\left(\frac{\mathrm{d} x}{\mathrm{~d} t}, x, y, p, d, u\right) \\
0=g(x, y, p, d, u) \\
0 \leq h(x, y, p, d, u)
\end{gathered}
$$

These equations represent a model that may include differential $\left(x, \frac{\mathrm{d} x}{\mathrm{~d} t}\right)$ or algebraic $(y)$ variables. Of these, some may be binary $(0,1)$, integer (e.g. $-1,0,1,2)$, or discrete (e.g. $0,1.71,5.1,7.2)$ variables. The solution to 
the equations can be given by the initial state $x_{0}$, parameters $p$, trajectory of disturbances $d=\left(d_{0}, d_{1}, \ldots, d_{n-1}\right)$, and control moves $u=\left(u_{0}, u_{1}, \ldots, u_{n-1}\right)$ 66]. The solutions for variables $x$ and $y$ are solved for each step $n$ of the time horizon from the differential (Eq. 1b), algebraic equality (Eq. 1c), or algebraic inequality (Eq. 1d) equations in the model. The formulation outlined in Eq. 1 is especially suitable to handle the complexities of an energy system capacity planning problem. The DAEs can describe differential and nonlinear physical features, while the explicit handling of disturbances as trajectories mimics the hourly energy demands over the time horizon. The solution method for a DAE model is summarized in the following section.

\section{Numerical Solution of DAE Systems}

Usually the time horizon of an energy capacity planning problem is on the order of decades because of the magnitude of the investment associated with capacity increases. The problem can become very large as the time horizon increases.

To solve dynamic optimization problems researchers and practitioners have used simultaneous 67] and sequential solution methods 68. More detail about each approach can be found in the literature 69], but the important aspect of the simultaneous method is the computational advantage for problems with many decision variables and a moderate number of state variables [66] as is the case with capacity planning problems over a long horizon. State variables can be seen as a set of variables used to describe the mathematical state of a dynamic system to determine the future behavior of the system [70. Simultaneous methods solve the DAE model by converting it to only algebraic equations in a method known as direct transcription [1]. This changes the problem to a nonlinear programming problem that can then be solved by large-scale optimization solvers 72 .

\section{Dynamic Optimization Framework}

DAE models are used in nonlinear predictive control and estimation applications such as industrial process fouling [73, unmanned aerial systems [74, drilling automation [75, systems biology [76, batch distillation [77, pipeline flow assurance [78 and many other applications. In a control environment, multiple objectives may be desired within a single control application. These objectives can have different priorities or rates at which they must be achieved. Similar multi-objective tradeoffs can exist in capacity planning because although cost minimization is the ultimate goal, certain environmental and operational objectives are also desired over the lifetime of the plant. These additional objective considerations have a significant effect on the capacity of the system [20, 21. Optimizing capacity investment timing and size alongside these important operational objectives is demonstrated in this work. One approach to handle the multi-objective challenge is the use of the $\ell_{1}$-norm formulation for nonlinear 
dynamic optimization. The $\ell_{1}$-norm formulation simultaneously optimizes the

multiple objectives by selectively manipulating the degrees of freedom that have the highest sensitivity on the most important objective, and then meeting the lower ranking objectives with the remaining degrees of freedom [79. Priorities are assigned by giving higher weighting to the most important objectives. The dynamic optimization $\ell_{1}$-norm objective formulation is shown in Eq. 2 .

$$
\min _{x, y_{m}, u} \Phi=w_{h i}^{T}\left(e_{h i}\right)+w_{l o}^{T}\left(e_{l o}\right)+\left(y_{m}\right)^{T} c_{y}+(u)^{T} c_{u}+(\Delta u)^{T} c_{\Delta u}
$$

s.t. Eqs.1b-1d

$$
\tau_{c} \frac{\mathrm{d} y_{t, h i}}{\mathrm{~d} t}+y_{t, h i}=s p_{h i}
$$

$$
\tau_{c} \frac{\mathrm{d} y_{t, l o}}{\mathrm{~d} t}+y_{t, l o}=s p_{l o}
$$

$$
e_{h i} \geq\left(y_{m}-y_{t, h i}\right)
$$

$$
e_{l o} \geq\left(y_{t, l o}-y_{m}\right)
$$

[Table 1 about here.]

The objective function for the $\ell_{1}$-norm formulation, Eq. 22, is a specific case of Equation 1. The most important distinction beneficial to a capacity planning problem is the ability to include other objectives such as trajectory targets or dead-bands that can be met at different response rates and levels of importance. Based on the $\ell_{1}$-norm formulation, the capacity planning problem can be framed as one cycle of an MPC problem. Manipulated variables such as CHP or boiler set points are moved by the optimizer to meet operating targets such as minimizing the error between energy production and demand over the entire planning horizon. At the same time, the capital and operating costs are minimized as part of the highest ranking objective function.

\section{The CHP Investment Model}

A district energy system may provide cooling and electricity with waste heat used to provide for the heating demand. In such arrangement, the buildings and cooling system represent the heating and cooling loads. The heat is provided by coal-fired or gas-fired boilers while the electric power supply comes from the $\mathrm{CHP}$ or the regional electrical grid. The heat produced from the boilers is used to provide all the energy for heating during the winter months as well as any auxiliary uses such as kitchens, showers, laboratories, etc. During the summer months, the boilers continue to operate to provide heat for absorption chillers 
and auxiliary uses. A conversion of a district energy system to one that includes

a CHP arrangement is illustrated in Figure 11. The arrangement includes important components such as 1.) gas turbine with generator for electricity, 2.) heat recovery boiler, 3.) back-up boiler capacity.

[Figure 1 about here.]

[Figure 2 about here.]

In this work, the objective function represents the sum of operating and capital cost over a 30 year horizon period as a function of key variables and parameters in the system. The 30 year energy demand horizon as shown in Figure 2 is built from average daily demand profiles and demand increase forecasts. Demand data for each year is reduced to demand profiles for an average winter day and an average summer day. To account for the total energy demand, the model multiplies each average hours value by $365 / 2$ to give the horizon for a simplified season (winter or summer) in a given year. To further reduce problem size, every two years' average daily profiles are averaged to obtain 15 summer day profiles and 15 winter day profiles. This assumes that the energy demand will be relatively constant every two years, and after a two-year period, demand increases. The handling of the demand data for model reduction is shown in Equation 15 which is discussed later in this section. Although the discretization of the horizon into average daily profiles gives 15 separate periods, the figures in this work are displayed as continuous for visualization purposes. For a complete description on the method to generate the electricity and heat demand horizon see [80. This work utilizes data from a turbine vendor [81 to construct empirical relationships through first-order and second-order polynomials for the important physical relationships. The data from the vendor is for small-size to medium-size industrial combustion turbines in the range of the capacity requirements for the district energy system considered in this study (1-30 MW). This work does not account for mechanical equipment degradation over time. It is assumed that to some degree, degradation effects are reversed by maintenance to turbine and boiler systems 82. In future work, a relationship to degradation over time could be explored. The objective and the equations that make up the deterministic energy system expansion model are first summarized in the following qualitative model formulation.

- Minimize: present value of capital and operating costs

- Subject to:

- Combined electricity production and electricity import supply must be greater than or equal to electricity demand.

- Utilized heat production capacity must be greater than or equal to heat demand.

- Utilized turbine and supplemental boiler capacity cannot exceed the maximum capacity of their respective systems. 
- Capacity investments are irreversible.

- Other physical and logical constrains that make the model feasible.

$-\mathrm{CO}_{2}$ calculations for environmental and cost constraints.

It is important to note that for this proposed optimization framework, there is no need to index or discretize the system by time and allocation of capacity. In the following model, the use of indices is only used to abbreviate equations and simplify notation. The subscript $s$ is used to denote the season (summer or winter) in which the system operates, but the entire model is solved simultaneously. In order to simplify the system, energy demand data for the summer and winter months are analyzed to derive two different representative summer day and representative winter day demand profiles. For a complete description of the method to generate the electricity and heat demand horizon see [80. The symbols are described in Table 2 .

[Table 2 about here.]

The semi-empirical mathematical description of the dynamic model is stated as follows.

\section{Minimize :}

The total operating and capital costs is the objective function given by:

$$
\sum_{s} O C_{s}+\sum_{p} C C_{p}
$$

The operating cost $\left(O C_{s}\right)$ for each season " $s$ " is summed for all steps in the time horizon as well as the capital costs $\left(C C_{p}\right)$ of capacity increases for system type " $p$ " at any step in the time horizon. The operating and capital cost functions are explained later in this section.

\section{Subject to Equations :}

Empirical first order differentials:

$$
\begin{gathered}
\tau_{\text {chp }} \cdot \frac{\mathrm{d} x_{s}}{\mathrm{~d} t}+x_{s}=u_{s} \\
\tau_{\text {boiler }} \cdot \frac{\mathrm{d} b_{s}}{\mathrm{~d} t}+b_{s}=v_{s}
\end{gathered}
$$

This work uses a first order differential equation model to fit turbine (Eq. 4) and boiler (Eq. 5) dynamic responses to power and heat generation respectively. A constrained differential term to describe both the timing and size of capacity investments is also demonstrated in this work. This work uses first order differential equations to model the hourly energy production as a response to a set point change. In a higher fidelity, shorter time-scale model, the fitting of $\tau$ would reveal the process time constant. The fitting process for the time constant can be accessed in common process control textbooks [83. In essence, $\tau$ or the time constant describes numerically how fast a system responds to a set point change. This can have large effects on the results of optimization as the time 
constant determines the dynamic response of a system. In this work, the $\tau$ for both the boiler and the CHP turbine is set to 0.024 hours for model simplicity. This means that the change in response to a set point is very fast. However, though the modeled change in response to a set point is too fast to model detailed process dynamics within each hour block, the hourly changes (or hourly dynamics) are incorporated into the long-term capacity planning problem. In a higher fidelity, shorter time-scale model, the time constants can and should be fit according to the actual dynamics of the system. However, the use of differentials and the $\ell_{1}$-norm formulation in this work adds simplicity in modeling and allows operational scenarios to be considered in the capacity investment problem rather than accounting for responses from the short-time-scale systems such as turbine and boiler dynamics.

Though the detailed dynamics on the minute and second scales are not accurately represented in this work, the formulation with first order differential equations means this formulation could be used with high-fidelity models given a large amount of computational power. The formulation also enables continuous time that is used for the capacity timing and sizing differential equations. The formulation as a differential equation also allows the use of the $\ell_{1}$-norm formulation to incorporate various operational scenarios and multiple objectives into the optimization problem. The APMonitor modeling and optimization package 66 allows the implicit use of time differentials to account for any time changes, both short and large scale, without further discretizing the system into large blocks. Future work should consider the more detailed dynamic effects of turbine and boiler system responses combined with large scale capacity allocation.

$$
\begin{array}{r}
y_{s}=-0.0817 \cdot x_{s}^{2}+5.6547 \cdot x_{s} \\
0 M W<x_{s}<30 M W
\end{array}
$$

Eq. 6 is a nonlinear interaction that describes the recoverable heat $y$ in a heat recovery boiler as a function of power production $x$ from the gas turbine. First principles models of turbines are available to detail the heat versus power response [28. A polynomial fit is sufficient in this work because heat recovery performance data for different turbine capacities operating at typical operating conditions is available from turbine manufacturers (see [80] for data and polynomial fit). The polynomial fit for this data, if extrapolated beyond the available data range, gives unrealistic properties because of the negative value coefficient; nevertheless, the optimization program is constrained to search only within the acceptable range. Exponential correlations of the data have better agreement than the polynomial fits, especially at smaller turbine capacities; however, exponential fits are more difficult to solve with optimization solvers because of strong nonlinear behavior. When exponential or logarithmic equations are coupled with other nonlinear equations in relatively large optimization problems, optimization solvers may not be able to find a solution. The total available heat supply to the district system is given by Eq. 7 which sums the boiler and CHP 
heat generation.

$$
h s_{s}=y_{s}+b_{s}
$$

Eq. 8a indicates the excess heat generation which is the difference between total heat production and heat demand. Because heat production can only come from the on-site system, the energy system is constrained to have a difference equal or greater than zero as indicated by Eq. $8 \mathrm{~b}$.

$$
\begin{gathered}
h e_{s}=h s_{s}-h d_{s} \\
h e_{s} \geq 0
\end{gathered}
$$

Usable heat production from a CHP system is limited by turbine capacity utilization, which means that at maximum load the maximum amount of heat is generated. Excessive heat production beyond the heat demand is discarded to the atmosphere through the flue combustion gases at higher temperatures. Although usually there are design and regulatory limitations on the flue gas temperatures, generally if too much excess heat is being discarded to the atmosphere, heat integration and efficiency goals of a CHP system are not being achieved. In the results and discussion section, optimization formulations to minimize excess heat $h e_{s}$ are explored. The net power relationship is given by

$$
n p_{s}=x_{s}-e d_{s}
$$

Many CHP systems have the convenience of interconnection with a larger power grid. Interconnection with a larger grid provides backup power, or if the CHP capacity is designed to partially fulfill the electric load, a larger grid can meet the remaining load. In certain markets net metering measures the difference between the electricity from the utility used by the customer and the electricity generated and provided back to the utility [84. Depending on the market where the CHP is located, net metering rates and incentives may make the CHP investment more financially attractive even after fuel and efficiency savings. Eq. 9 defines the net power usage of the system to simulate the net metering options of certain markets. When the CHP power production $x_{s}$ is greater than the electric demand $e d_{s}$ then the excess electricity is sold back to the grid. On the other hand, if electric demand is greater than the current CHP power production, the resulting negative $n p_{s}$ denotes that power is being imported from the external electrical grid. This flexibility makes for even greater optimization trade-offs that can affect capacity planning of CHP systems. In this work, both net metering and electricity import only options are explored in different optimization cases. For simplicity when net metering is allowed, the same electric rates are considered for either import or export of electricity. Although this is a simplification of more complicated net metering rules, it provides a good basis to explore the realistic effects of such trade-offs in energy system capacity planning. 
Turbine load fraction and efficiency are given by:

$$
\begin{gathered}
l f_{s}=\frac{x_{s}}{m c_{c h p}} \\
\eta c_{s}=0.9044 \cdot l f_{s}+0.0956 \\
0<l f_{s}<1
\end{gathered}
$$

The natural gas consumption for CHP and boiler are given by:

$$
\begin{gathered}
f c_{s}=\frac{-0.1361 \cdot x_{s}^{2}+13.347 \cdot x_{s}}{\eta c_{s}} \\
0 M W<x_{s}<30 M W \\
f b_{s}=\frac{b_{s}}{\eta b}
\end{gathered}
$$

When less than full power is required from a gas turbine, the output is

474

reduced by lowering the turbine inlet temperature. This reduction also reduces efficiency [6. The load fraction $l f_{s}$ is the ratio of instantaneous CHP output and CHP capacity. When the turbine is operating at its maximum capacity load fraction is 1 . Turbines in the range of capacity considered in this work generally reach a maximum efficiency around $30 \%$. The turbine load versus efficiency relationship is normalized to $1(100 \%)$ for maximum efficiency and a linear relationship is approximated by Eq. 10b. This is done because fuel consumption from manufacturer data for different turbine capacities is rated at the maximum load, at the most efficient state. In other words, the maximum capacity of the turbine as defined in this work is the functional maximum capacity, not the theoretical maximum capacity. The CHP fuel consumption (Eq. 11a) is also represented by a polynomial fit from manufacturer data for gas turbines running at optimal full capacity. Operation below the turbine's rated capacity consumes more fuel, thus the polynomial for fuel consumption is divided by the normalized CHP efficiency $\eta c_{s}$ to estimate the effects of part load operation on fuel consumption. When the normalized CHP efficiency is less than one, fuel consumption increases thus quantifying the effects of operating the gas turbine at less than full capacity. Fuel consumption by the gas boiler (Eq. 11b is estimated by directly dividing the boiler energy output by the expected boiler efficiency of $80 \%$.

Carbon dioxide calculations are given by:

$$
\begin{gathered}
c e_{c h p, s}=c n / 2000 \\
c e_{\text {boiler }, s}=c n / 2000
\end{gathered}
$$


The $\mathrm{CO}_{2}$ emissions rate from fuel consumption estimated by Eqs. 12a and

496

$12 \mathrm{~b}$ are based on a stoichiometric relationship of natural gas combustion. When there is a cost associated with $\mathrm{CO}_{2}$ emissions, the cost is calculated by:

$$
c t_{s}=\left(c e_{c h p, s}+c e_{\text {boiler }, s}\right) \cdot c p \cdot(907.185 / 1000)
$$

The capital and operating cost functions are given by:

$$
\begin{array}{r}
C C_{\text {chp }}=\left(-0.0069 \cdot\left(\triangle m c_{\text {chp }}\right)^{2}+1.3351 \cdot\left(\triangle m c_{c h p}\right)\right) \cdot\left(10^{6}\right) \\
\cdot(1+i r)^{y r} \cdot(1+d r)^{-y r} \\
0 M W<\Delta m c_{c h p}<30 M W \\
C C_{\text {boiler }}=2 \cdot\left(-39.504 \cdot\left(\triangle m c_{\text {boiler }}\right)^{2}+29900 \cdot\left(\Delta m c_{\text {boiler }}\right)\right) \\
\cdot(1+i r)^{y r} \cdot(1+d r)^{-y r} \\
0 M M B T U / h r<\Delta m c_{\text {boiler }}<200 M M B T U / h r
\end{array}
$$

Correlating the capital costs is important for an accurate objective function. Polynomial approximation of manufacturer data on capital costs for a range of CHP capacities is used for the CHP capital cost function. The data comes from a survey of estimated total capital costs for typical gas turbine-based CHP systems [81, 80]. One of the innovations of this work is in using differential equations that explicitly consider system changes with respect to time for capacity planning problems. Over the entire time horizon the energy generation capacities may increase when the energy demands requires expansion, but those changes are also limited by the economic objective of minimizing costs. In Eqs. 14a and 14b. $\triangle m c_{p}$ denotes the change in maximum capacity of system $p$. To describe this in the optimization program, the multiplication operation $\triangle t \cdot \frac{\mathrm{d} m c_{p}}{\mathrm{~d} t}$ yields an approximation to $\triangle m c_{p}$, the magnitude of the maximum capacity change at a particular time period. The differential time change $\mathrm{d} t$ is approximately equal to the time discretization $\Delta t$ interval used in the model. The optimization software used in this work explicitly handles differential equations, which allows for the calculation of capital cost at any time period of the horizon at which the optimizer finds optimal to have a change in capacity in the energy system. The capital cost equations are multiplied by $(1+i r)^{y r}$ to account for inflation and and by $(1+d r)^{-y r}$ to account for the time value of money. The capital costs are summed together and included as minimization terms in the objective function Eq. 3. The operating cost is evaluated by:

$$
O C_{s}=\left(n g \cdot f c_{s}+n g \cdot f b_{s}-e e \cdot n p_{s}+c t_{s}\right) \cdot(0.5 \cdot 365 \cdot n) \cdot(1+d r)^{-y r}
$$

The operating expenses CHP fuel, boiler fuel, net electric power, and $\mathrm{CO}_{2}$ emissions are summed and multiplied by $(0.5 \cdot 365 \cdot n)$ to approximate the number of days (half a year) in each season $S$. The letter $n$ is the number of years 
each demand cycle represents, and is used to reduce the number of individual cycles the optimization program must solve. In this study each demand cycle represents two years $(n=2)$. The operating cost equation also contains the term $e e \cdot n p_{s}$ which quantifies the cost of electricity. This term has a negative sign because net power $\left(n p_{s}\right)$ is positive when excess electricity is produced.

528 Excess electricity production reduces operating cost because it is sold to the grid. When electricity is imported $n p_{s}$ is negative which causes the $-e e \cdot n p_{s}$ 530 term to be positive and the operating cost to increase. Operating costs are also discounted to the present value by $(1+d r)^{-y r}$. There is no inflation factor ${ }_{532}$ in Eq. 15 because the natural gas and electricity price data already considers inflation. It is important to note that $\mathrm{CO}_{2}$ emissions cost $\left(c t_{s}\right)$ is only considered in economic scenarios that give $\mathrm{CO}_{2}$ a cost associated per ton emitted. The baseline scenarios in this work do not consider $\mathrm{CO}_{2}$ emission cost but some scenarios with $\mathrm{CO}_{2}$ cost are explored in this work. To specify the irreversible nature of change in capacity, the differential terms are directly constrained by:

$$
\begin{gathered}
\frac{\mathrm{d} m c_{c h p}}{\mathrm{~d} t} \geq 0 \\
\frac{\mathrm{d} m c_{\text {boiler }}}{\mathrm{d} t} \geq 0
\end{gathered}
$$

Directly constraining differential terms is a feature that few optimization software packages have, but is extensively exploited in this work by utilizing the APMonitor package [66]. Limiting $\frac{\mathrm{d} m c_{p}}{\mathrm{~d} t}$ to be $\geq 0$ allows for the change in maximum capacity of system $p$ to remain positive meaning there is no decrease 542 in capacity once a decision is made. The maximum capacity always remains greater than or equal to the instantaneous generation rates of the CHP and 544 boiler system respectively through the following constraints:

$$
\begin{gathered}
m c_{c h p} \geq x_{s} \\
m c_{\text {boiler }} \geq b_{s}
\end{gathered}
$$

In summary, the dynamic model includes all the potential energy generation systems to fulfill the heating and electric demands. The optimizer decides which arrangement and capacity is needed. The optimizer can either decide to have

548 a CHP only system, a boiler only, or a combination of the two along with the choice of import capacity from the grid for electricity. The optimizer uses the 550 model to find timing and potential overall capacity in a 30 year horizon by minimizing total present value costs as stated in the objective function Eq. 3.

\section{Uncertainty in Natural Gas and Electricity Prices}

With uncertainty in natural gas and electricity prices, there is motivation to 554 optimize the problem to the expected value of the total capital and operating 
cost over the time horizon. Natural gas and electricity prices are stochastic inputs to the model represented by the uncertain future spread of prices over the optimization horizon as illustrated in Figure 3 below. The 30 year horizon from 2010 to 2040 is chosen for this study due to availability of long-horizon projection data (current available projections only span through 2040). Commercial enduser price projections from the U.S. Energy Information Administration (EIA) are utilized (see [85, 86]). Based on the likelihood of each economic model, there 562 is a specific probability associated with each value of natural gas and electricity price. At any particular point in the time horizon the probability of all the ${ }_{564}$ possible values of a random variable can be summarized by a probability mass function $(\mathrm{PMF})$ if the random variable is discrete [87. It is often desirable to summarize the probability information in a single representative number. That is accomplished by a deterministic value, also called the expectation or the mean, of a random variable, which is a weighted average of the possible values of the random variable 87 .

[Figure 3 about here.]

The expectation of a random variable $X$ is mathematically defined as

$$
E[X]=\sum_{x} x \cdot p x(x)
$$

where $p x(x)$ is the probability associated with each variable $x$. For linear function of random variables it can be verified that the expected value of a function of the form $a \cdot X+b \cdot Y+c$ is given by $a \cdot E[X]+b \cdot E[Y]$ where $X$ and $Y$ are random variables and $a, b$, and $c$ are scalars and $x, u, p, d$, and $u$ are other non-stochastic variables affecting the system. This property is extended to find the expected value of the total cost. If the total present cost $(P C)$ function is of the form shown in Eq. 19.

$$
\begin{aligned}
P C= & f_{1}\left(\frac{\mathrm{d} x}{\mathrm{~d} t}, x, y, p, d, u\right) \cdot A+f_{2}\left(\frac{\mathrm{d} x}{\mathrm{~d} t}, x, y, p, d, u\right) \cdot A \\
& +f_{3}\left(\frac{\mathrm{d} x}{\mathrm{~d} t}, x, y, p, d, u\right) \cdot B+f_{4}\left(\frac{\mathrm{d} x}{\mathrm{~d} t}, x, y, p, d, u\right)
\end{aligned}
$$

$f_{1}$ through $f_{4}$ in Equations 19 and 20 represent nonlinear functions for CHP fuel consumption (Eq. 11a), boiler fuel consumption (Eq. 11b), net power production (Eq. 9), and capital costs (Eqs. 14a|14b), respectively. The parameters $A$ and $B$ are the stochastic natural gas price and electricity price respectively. Although the $P C$ is the result of a highly nonlinear system, each function $f$ does not depend on the stochastic $A$ and $B$ parameters. Because this dynamic optimization simultaneously solves each time step and does not depend on feedback from previous solutions, the expected value of the $P C$ at each time step 
reduces to

$$
\begin{aligned}
E[P C]= & f_{1}\left(\frac{\mathrm{d} x}{\mathrm{~d} t}, x, y, p, d, u\right) \cdot E[A]+f_{2}\left(\frac{\mathrm{d} x}{\mathrm{~d} t}, x, y, p, d, u\right) \cdot E[A] \\
& +f_{3}\left(\frac{\mathrm{d} x}{\mathrm{~d} t}, x, y, p, d, u\right) \cdot E[B]+f_{4}\left(\frac{\mathrm{d} x}{\mathrm{~d} t}, x, y, p, d, u\right)
\end{aligned}
$$

Eq. 20 shows that the uncertainty associated with natural gas and electricity prices on the PC at each time step is captured only by the expected value of each random variable as defined in Eq. 18. This is true after the assumptions established earlier that the energy demand is considered a deterministic input and there is negligible uncertainty on model parameters and initial conditions. Otherwise all functions $f$ are random functions whose PMFs would be very difficult to obtain because of the nonlinear nature.

To find the expected natural gas and electricity price, the probabilities of each price data point must be known. Statistical analysis using the MATLAB statistical toolbox constructs probability density functions (PDFs) and cumulative density functions (CDFs) of the price data for each year in the horizon to estimate the probability of each data point. MATLAB statistical toolbox uses a kernel distribution to estimate PDFs. A kernel distribution is a nonparametric representation of the PDF of a random variable. This method is employed when a parametric distribution cannot describe the data or to avoid making assumptions about the distribution of the data 88. Eq. 19 is invoked to find the expected value of natural gas and electricity prices. If each economic model is assumed to have equal probability, the deterministic value of natural gas and electricity prices at each year is the arithmetic mean, a very simple computation. The calculated deterministic values for both natural gas and electricity prices at each year are used as the price inputs in Eq. 15 to calculate the operating cost. This makes the objective function Eq. 3 similar to Eq. 20, the expected value of the total net present value costs. The stochastic information is encapsulated in the deterministic natural gas and electricity prices and incorporated in the optimization directly through the objective function.

\section{Results and Discussion}

The objective of this work is to evaluate the optimal CHP capacity investment schedule for a district energy system through dynamic optimization and the $\ell_{1}$-norm formulation (see Eq. 2). This approach opens the flexibility of posing the capacity investment problem as an optimal control problem. This approach aims at addressing some of the disturbances that may affect approaching a single investment scenario through a single optimization formulation. Through this approach stakeholders can evaluate not only the common global cost minimization objective but also introduce control objectives to operational variables that can affect the overall capacity and investment schedule over a large time 
horizon. The different optimization evaluations to a single economic scenario are first summarized in Table 3. The table compares six different optimization cases of the district energy model described earlier in this work. Each case evaluates a different aspect of the control objectives with its corresponding results in capacity, costs, and levelized cost of usable energy. It is worth noting that cases A-F do not take $\mathrm{CO}_{2}$ cost into account, but section 12 includes cases which account for multiple possible scenarios with variable $\mathrm{CO}_{2}$ cost. Parameters used for cases A-F are detailed in Table 4.

\section{[Table 4 about here.]}

The last column of Table 3 is the levelized cost of energy. This is an important parameter used to compare, through a single number, the cost of energy over the lifetime of the system. It is defined as

$$
\frac{\sum_{t=1}^{n} C C_{t}+O C_{t}}{\sum_{t=1}^{n} E_{t}}
$$

where $C C_{t}$ is the discounted capital cost at time $t, O C_{t}$ is the discounted operating cost at time $t, E_{t}$ is the usable energy generation at time $t, n$ is the life of the system. The sum of usable energy $\left(E_{t}\right)$ is the sum of both electric and usable thermal energy in megawatt-hours, but does not account for thermal energy that is wasted through the flue gas. The levelized cost of energy is a useful tool to evaluate which generation system option produces energy in the most cost effective way.

The overall monetary and capacity results alone may provide interesting insights, but the evaluation of additional objectives within the same model can provide stake holders information in mode of operation, utilization of capacity, and time dependent parameters that affect the overall cost, capacity, and schedule of the investment. Such an approach provides granularity and insights into the variables affecting the size and schedule of the investment that otherwise would be unknown, thus providing greater certainty to large, upfront investments.

[Figure 4 about here.]

[Figure 5 about here.]

[Figure 6 about here.]

[Figure 7 about here.]

[Figure 8 about here.]

Table 3 summarizes the final capacity for the different optimization cases, but Figure 4 shows the exact timing and magnitude of the investments over the 30 year horizon period. For CHP Capacity investment, every case suggests an investment of capacity within the first year of evaluation, in other words as soon 
as investment is possible. It is notable that there are small subsequent jumps in capacity expansion for 3 of the cases that eventually converge to an installed capacity of $11 \mathrm{MW}$. The smaller increments are mainly a function of the models inability to quantify for the larger cost per MW of capacity investment at scales smaller than typical large-scale CHP projects. In a more realistic scenario, the incremental CHP capacity increases across the horizon suggested by the optimization could be combined to a larger increase at the time of the first forecast need. Future work will address the smaller increments through model enhancements to the capital cost equations for CHP investment.

The boiler capacity schedule shows a more staggered approach to capacity increases, with some models requiring significant increase 10 to 15 years after the initial CHP installation. Small, modular boiler capacity increases across the horizon are more realistic than small capacity increases in CHP turbine systems. Additionally, boiler systems can be reconfigured for small increases in capacity with the addition of burners and piping to increase heat transfer with a smaller investment cost to existing equipment. The ability of this optimization approach to holistically account for the capital cost as well as the operating cost relationship to turbines and boiler efficiency are key in evaluating more realistic investment scenarios and reducing the risk of over-investment or underinvestment. Next is a discussion for the specific differences in optimization approach between cases and their influence on the capacity and schedule result.

\subsection{Case $A$}

This case is considered the base case scenario as it only includes the economic objective of reducing all cost in present value while meeting the power and heat demands of the district energy system. As shown in equation 22 the heat demand is constrained to be met by constraining error heat to be non-negative and net power is constrained to be less than or equal to zero, meaning no electricity may be sold to the grid.

$$
\begin{array}{r}
\min E[P C] \\
h e_{s} \geq 0 \\
n p_{s} \leq 0
\end{array}
$$

The optimal CHP capacity investment begins from the beginning of the horizon and remains stable without calling for additional potential increases in CHP capacity throughout the horizon, as seen in Figure 4. The CHP also remains operationally stable as electricity is produced at maximum capacity for most of the winter demands and for all of the summer demands as indicated in Figures 7 and 8 . The results show that the turbine capacity is set by the optimizer based on the lowest base load demand of the horizon. This allows for the turbine to be utilized at its highest most efficient load over the entire horizon at all times. Figures 5 and 6 show that during the summer months the heat demand is met by the turbine heat supply while for the winter months additional heat is needed to meet demand. Thus, expanded boiler capacity is 
required later in the horizon. The boilers are operational only during the winter

\subsection{Case $B$}

As indicated by Table 3 , every case in this study evaluates the economic objective equation in the model, or Equation 3 which calculates the sum of all operating and capital costs in present dollars. Case B introduces the $\ell_{1}$-norm formulation to keep a control variable, excess heat production (Equation 8a), above a lower bound soft constraint. These lower bounds are referenced as soft constraints because they can be violated with a cost to the objective function proportional to the difference with the given bounds. Evaluating this optimization problem with a dead-band or just upper or lower bounds on excess heat production removes the need for the explicit excess heat constraint (Equation 8b. As part of the $\ell_{1}$-norm formulation, the control variables can be set to follow a band where they are free to fluctuate without penalty. Violation of the control bounds by the control variable $(\mathrm{CV})$ is penalized by a weight factor that can be set at different magnitudes for the upper or lower bounds set points as shown in Equation 2 where $w_{h i}$ and $w_{l o}$ are penalty weights. These upper and lower bound set point weights act on the objective function when the control variable crosses the set bounds. The base model contains the excess heat constraint Equation $8 \mathrm{~b}$, but in Case B Equation $8 \mathrm{~b}$ is removed to evaluate the results of utilizing only the lower bound set point on the excess heat CV. The lower band set point is set at $10 \mathrm{MMBTU} / \mathrm{HR}$ to attempt to guarantee slight excess heat. The lower band violation has a weight of $10^{6}$ while the upper has a weight of zero. The lower band boundary penalty must be more severe as excess heat below zero would trigger under-production of heat energy. A weighting factor of zero is set for the upper band to indicate that excess production of heat energy is not penalized.

$$
\begin{array}{r}
\min E[P C] \\
-\infty<h e_{s}<\infty \\
n p_{s} \leq 0 \\
w_{h i}=0 \\
w_{l o}=10^{6} \\
s p_{h i}=0 \\
s p_{l o}=10
\end{array}
$$

This case demonstrates the viability and flexibility of soft constraints through dead-band guidance on CV in a capacity investment schedule optimization prob704 lem. Violations on excess heat energy below zero as shown in Figures 9 and 10 for Case B indicate that the optimization finds under-production of heat during 706 brief periods optimal. In a real scenario, under-production of heat is generally unacceptable; however, this formulation provides deeper insight into other op708 tions. In evaluating power generation capacity investments, stake holders many 
times must assess the viability of always meeting energy demands through in-

creases in capacity which may only be used during peak periods, or manage the peak usage though other more cost effective ways such as shifting energy demands to other times of the day or shutting down equipment. Stake holders can also consider energy storage capabilities for shifting energy demands. Further work should explore investment and operational models which integrate these peak load shifting options.

[Figure 9 about here.]

[Figure 10 about here.]

\subsection{Case $C$}

This case maintains the same formulation as Case A with the exception of the removal of the inequality constraint on net power. If left unconstrained, Equation 9 in the model indicates the variable is allowed to go either negative or positive. If positive, the system is producing electric power above the systems demand. The excess electric power is allowed to be sold to the grid and thus counts as positive cash flow in the operating cost evaluation.

$$
\begin{array}{r}
\min E[P C] \\
h e_{s} \geq 0 \\
-\infty<n p_{s}<\infty
\end{array}
$$

As expected, the results show that the optimization finds driving the CHP capacity to the given maximum 30MW optimal, as shown in Figure 4 . Without the inequality constraint, the system behaves as a power plant for export rather than meeting the systems demand at the lowest cost. Although attractive due to overall cost reduction resulting from revenue, this system has higher cost per megawatt hour than Case A, as indicated by the levelized cost of energy evaluation. In addition to the higher cost per MW-hr, the model greatly simplifies the revenue structure which does not account for the very complex environmental regulations and uncertainties in the business of power generation as well as the additional maintenance costs. The higher levelized cost of energy for this case can also be explained by the fact that although the solution suggests increasing capacity to behave as a major power plant, the limitations in size and scope for the CHP system restrain it from fully attaining the economies of scale and tri-generation benefits of utility scale power plants which usually have the lowest levelized cost of energy. This case highlights the ability of this optimization framework to easily evaluate operational scenarios through explicit constraint changes that do not require major reconfiguration on the model and its assumptions. 


\subsection{Case D}

$744 \quad$ Case D applies an upper bound limit to restrain heat energy over-production. The upper bound limit on excess heat is set at $20 \mathrm{MMBTU} / \mathrm{hr}$ with a weight

746 of $10^{5}$. If the excess heat energy crosses the $20 \mathrm{MMBTU} / \mathrm{HR}$ upper bound, the penalty adds cost to the combined objective function as illustrated in Equation $748 \quad 2$.

$$
\begin{array}{r}
\min E[P C] \\
h e_{s} \geq 0 \\
n p_{s} \leq 0 \min E[P C] \\
w_{h i}=10^{5} \\
w_{l o}=0 \\
s p_{h i}=20 \\
s p_{l o}=0
\end{array}
$$$$
h e_{s} \geq 0
$$

The result of the upper bound $\mathrm{CV}$ limit is a dramatic reduction of excess heat production. Figures 9 and 10 show that the excess heat energy curve remains at zero in both seasons over the entire horizon. This is the only case where excess heat production levels out at zero, constrained by Equation 8b for both seasons. It is also important to analyze that the effect of the $\mathrm{CV}$

754 bounds have a noticeable effect on the overall problem, and thus differences in operational scenarios arise to meet the constraints, or violate them, both have 756 an effect on the utilization of capacity. For example, Figure 9 shows Case D is the only instance where the electricity production for the summer season follows

758 the heat production, rather than topping off at the CHP maximum or following the electricity demand. The levelized cost of electricity is the highest among 760 all cases, indicating that perturbation on the problem by the CV upper bound soft constraint, even with small penalties, can have a significant effect on the utilization of capacity but do not affect the overall CHP and boiler capacity and timing of the investment.

\subsection{Case $E$}

Case $\mathrm{E}$ was formulated to observe the effects of a weak lower bound set point penalty. The hard constraint in the model on excess heat, Equation $8 \mathrm{~b}$ remains active, but a lower bound set point on the excess heat $\mathrm{CV}$ is set at 10 ${ }_{768} \mathrm{MMBTU} / \mathrm{HR}$ and no upper bound set point is applied.

$$
\begin{array}{r}
\min E[P C] \\
h e_{s} \geq 0 \\
n p_{s} \leq 0
\end{array}
$$




$$
\begin{array}{r}
w_{h i}=0 \\
w_{l o}=10^{6} \\
s p_{h i}=0 \\
s p_{l o}=10
\end{array}
$$

The result is that due to the weak lower set point weight, the optimization

finds keeping excess heat above the hard constraint optimal but does not find keeping the excess heat above the soft constraint of $10 \mathrm{MMBTU} / \mathrm{hr}$ optimal. The CV violated the soft constraint to provide lower overall cost.

\subsection{Case F}

Case $\mathrm{F}$ contains both a lower and upper set point on the excess heat $\mathrm{CV}$ dead-band at $10 \mathrm{MMBTU} / \mathrm{HR}$ and $20 \mathrm{MMBTU} / \mathrm{HR}$ respectively. The weight factor for CV band violations for both upper and lower bounds is set at $10^{5}$.

$$
\begin{array}{r}
\min E[P C] \\
h e_{s} \geq 0 \\
n p_{s} \leq 0 \\
\\
w_{h i}=10^{5} \\
w_{l o}=10^{5} \\
s p_{h i}=20 \\
s p_{l o}=10
\end{array}
$$

As shown in Figures 9 and 10 summer and winter excess heat supply respectively track very closely with minor variations the results for Case E. The results never violate the upper bound of $20 \mathrm{MMBTU} / \mathrm{HR}$ but the lower bound is consistently violated as is in Case E. The likely explanation is that the lower set point band creates a tendency for the excess heat CV to rise but not enough to rise above the lower bound CV set point of $10 \mathrm{MMBTU} / \mathrm{HR}$. The upper bound of $20 \mathrm{MMBTU} / \mathrm{HR}$ is never violated, but perhaps the perturbation this upper bound creates in the optimization space creates the small differences that tend to push the excess heat CV lower as opposed to Case $\mathrm{E}$ which does not have an upper bound set point. In other words, Case $\mathrm{E}$ has a tendency to have more excess heat than Case F because there is no upper bound limiting Case E.

\subsection{Overall Discussion}

Overall, the addition of excess heat energy as a control variable on top of the monetary cost minimization incorporates operational scenarios with the optimal capacity problem. These operational what-if scenarios are a novel method to evaluate the robustness of the economic-only cost minimization solution. As 
shown in the results of cases $\mathrm{B}$ and $\mathrm{D}$ through $\mathrm{F}$, when attempting to control the excess heat $\mathrm{CV}$ within a band or above or below a target, the CHP capacity is lowered to $11 \mathrm{MW}$ and boiler capacity is greatly increased. These evaluations show additional flexibility of the capacity investment with a system that reacts to changes in either electricity or heat generation regardless of the target value. The mix of CHP and larger boiler capacity adds overall cost, but operational flexibility, especially in uncertain regulatory and economic environments, may be more cost effective if taken into account early in the investment schedule instead of over-investing in CHP capacity and paying in the form of sub-optimal operation of a CHP turbine system. Integration of operational and capacity decisions is seldom utilized, yet it provides greater granularity to help confirm or question capacity investment when only cost reductions are evaluated. In conclusion, the cases in this study show that a CHP system with $11 \mathrm{MW}$ power generation maximum capacity and boiler capacity with a minimum of 50 MMBTU/HR would be a reasonable investment to cover different operational scenarios around excess heat generation for the district energy system. The exploration of the effects of additional combinations of operational objectives on capacity investment scheduling is beyond the scope of this paper. However, the demonstrated formulation can be applied to other operational control objectives in district energy systems as well as other types of systems to evaluate capacity investment decisions under variable operational scenarios.

\section{Optimization Under Uncertainty with Future Economic Scenarios}

For long-term energy system planning, it is important to understand the sensitivity of the result to uncertain future energy prices or policies. This section contains optimization results based on different economic and policy scenarios. The results directly reflect the effect of different economic data with the same equations and objective function. Case $\mathrm{A}$ is selected for the sensitivity study although any of the cases could be used for this analysis. Case A does not restrict excess heat generation, allows import of electricity from grid, and does not allow export of electricity to the larger grid.

\subsection{Economic Scenarios}

Optimizing capacity planning under different economic scenarios beyond the expected natural gas and electricity prices generate results that give insights on the sensitivity of the capacity and timing of investment on energy prices. Figure 11 shows a distribution of future costs for natural gas (\$/MMBTU), electric grid

power $(\$ / \mathrm{MW}-\mathrm{hr})$, and $\mathrm{CO}_{2}$ emissions (\$/tonne).

[Figure 11 about here.]

The optimization results are restricted to integer increments (e.g. 10 or 11 instead of 10.2) for CHP capacity and increments of 5 for boiler capacity (e.g. 0, 5,10 , etc.). Integer formulations are computationally harder to solve, but give more realistic results because of discrete sizes that are common from vendors. 
For example, turbine capacities are usually rated by integer number (e.g. 10 MW) instead of a mixed number (e.g. 10.14 MW). Results for the mixed integer nonlinear programming (MINLP) problem are summarized in Figure 12 for the set of 27 economic scenarios. Optimization of a wide range of economic scenarios gives insights about the feasibility of a CHP system.

[Figure 12 about here.]

For most of the economic scenarios, the CHP maximum capacity recommendations are closely aggregated between $9 \mathrm{MW}$ and $13 \mathrm{MW}$ capacity, a difference of just $4 \mathrm{MW}$ in capacity (see Figure 14. Although a $4 \mathrm{MW}$ spread translates to differences in several million dollars in capital investment, the optimization solution provides less uncertain capacity options because more information about the system is encapsulated and solved simultaneously. It is important to mention that for all cases where CHP capacity is cost effective, the capacity investment starts from the beginning of the horizon. Figure 13 also shows the frequencies of the maximum boiler capacities. The boiler capacity increases are distributed at different points of the horizon.

There are five cases where the optimization finds a lower objective function without CHP investment. These results are less intuitive to understand, but underscore the benefits of large scale dynamic optimization formulations that utilize large sets of data and solve the problem simultaneously for the entire horizon. The economic evaluations are performed at every step of the horizon, thus the hidden trade offs from the economic data inputs at different time points are exploited to find an overall lower cost objective. Future work should investigate the details of these solutions.

[Figure 13 about here.]

[Figure 14 about here.]

For a district energy system, the size of the capacity investment strongly depends on the financial incentive that the optimizer finds based on the uncertain fuel cost and electricity price data. In contrast, without a simultaneous optimization with uncertain parameters, CHP designs may be arbitrarily oversized to deal with the uncertainty. Oversized CHP capacity options not only increase already expensive capital expenditures, but also CHP utilization will be more expensive because there is a greater opportunity for the gas turbine to operate at lower, less efficient loads over the lifetime of the system.

Difficulty in solving large and highly nonlinear dynamic optimization problems is something that is still challenging and the subject of continuous research. This limitation is visible in this work in using second degree polynomials instead of better fitting exponential functions for capacity vs. cost relationships. The optimizer in certain cases recommends smaller increases in boiler capacity throughout the horizon, which may be an artifact of the slightly nonlinear polynomial functions. Close to the origin, the polynomial fits are almost linear; therefore, smaller capacities give smaller cost and potentially an artificially lower 
objective. Limitations also exist in this work when formulating the problem to explicitly account for uncertainty by introducing larger amounts of data into the problem. The optimizer handles 20463 state variables, 18309 total equations, and 2872 slack variables, with over 700 degrees of freedom when considering a single economic case. When different economic cases are simultaneously solved, the optimization solver is unable to solve the problem. Future work should explore improving optimization solver start up procedures as well as consideration of alternative large scale optimization solvers to diminish both the highly nonlinear and large problem limitations.

To further understand and differentiate the effects of important economic parameters, future work should explore global optimization techniques to verify global optimality from given economic inputs. This work does not include a comprehensive study on the global optimality of the solutions, but mainly focuses on a gradient based dynamic optimization strategy for energy system capacity expansion problems. This work does not attempt to show an exhaustive capacity investment schedule for a district energy system, but rather demonstrate that a dynamic optimization framework is a feasible approach to guide capacity planning of energy systems. This approach can be expanded to larger systems such as smart grid applications where a number of interactive energy systems with unique dynamics such as coal power plants, wind and solar renewable power sources, energy storage, and carbon capturing systems interact to meet demands. The intrinsic dynamics, economic, and operational targets affect capacity and timing of investments of system components. This optimization framework brings a holistic approach to handle multiple targets and system data within a single optimization formulation.

\section{Conclusions}

This work presents a dynamic optimization case study for capacity planning of a district energy system. The modeling of the district energy system along with the formulation to find the capacity investment over a 30 year horizon is facilitated by the use of differential and algebraic equations, including directly constrained differential equations describing the capacity investment timing and size. The differential elements explicitly account for changes in capacity over time without the need to explicitly discretize the model to account for time as is done in traditional linear programming formulations. For this application, differential terms describe both long time-scale capacity investment decisions and short time-scale operational scenarios. This cannot be done in models that do not treat time as a continuous, explicit variable. This work also shows that within the dynamic optimization framework the objective function can include other control objectives with the economic objective. The $\ell_{1}$-norm formulation inserts operational control objectives in the optimization formulation to observe the short term effects on long term capacity planning. Different economic cases also affect capacity and timing of the investment. This optimization framework is a tool to guide timing of capacity investments that reflect operational strategies and multiple objectives. This optimization framework may 
guide decision-makers to more effectively avoid issues of sub-optimal capacity utilization, insufficient capacity, loss of cost-effectiveness, as well as other issues encountered in the past.

\section{References}

[1] D. Patiño Echeverri, P. Fischbeck, E. Kriegler, Economic and environmental costs of regulatory uncertainty for coal-fired power plants., Environmental science \& technology 43 (3) (2009) 578-84, ISSN 0013-936X, URL http://www.ncbi.nlm.nih.gov/pubmed/19244986.

[2] L. Tuthill, Investment in Electricity Generation Under Emissions Price Uncertainty : The Plant-Type Decision, Tech. Rep. June, The Oxford Institute for Energy Studies, 2008.

[3] M. Meckler, Sustainable On-Site CHP Systems: Design, Construction, and Operations Contributors, The McGraw-Hill Companies, Inc., New Yortk, 2010 .

[4] K. Kelly, M. McManus, G. Hammond, An energy and carbon life cycle assessment of industrial CHP (combined heat and power) in the context of a low carbon UK, Energy 77 (2014) 812 - 821, ISSN 0360-5442.

[5] H. Lee, J. Bush, Y. Hwang, R. Radermacher, Modeling of micro-CHP (combined heat and power) unit and evaluation of system performance in building application in United States, Energy 58 (2013) 364 - 375, ISSN 0360-5442.

[6] U.S. Environmental Protection Agency, Catalog of CHP Technologies, Tech. Rep., URL www.epa.gov/chp/documents/catalog_chptech_full. pdf, 2008.

[7] S. M. Safdarnejad, J. D. Hedengren, L. L. Baxter, L. Kennington, Investigating the Impact of Cryogenic Carbon Capture on the Performance of Power Plants, in: Proceedings of the American Control Conference (ACC), Chicago, IL, 5016-5021, 2015.

[8] S. M. Safdarnejad, J. D. Hedengren, L. L. Baxter, Plant-level dynamic optimization of Cryogenic Carbon Capture with conventional and renewable power sources, Applied Energy 149 (2015) 354 - 366, ISSN 0306-2619.

[9] S. Safdarnejad, J. Hedengren, L. Baxter, Dynamic Optimization of a Hybrid System of Energy-Storing Cryogenic Carbon Capture and a Baseline Power Generation Unit, Applied Energy 172 (2016) 66-79.

[10] A. Nosrat, J. M. Pearce, Dispatch strategy and model for hybrid photovoltaic and trigeneration power systems, Applied Energy 88 (9) (2011) 3270 - 3276, ISSN 0306-2619. 
[11] J. M. Pearce, Expanding photovoltaic penetration with residential distributed generation from hybrid solar photovoltaic and combined heat and power systems, Energy ISSN 03605442.

[12] R. Wang, P. Wang, G. Xiao, A robust optimization approach for energy generation scheduling in microgrids, Energy Conversion and Management 106 (2015) 597 - 607, ISSN 0196-8904.

[13] J. Du, J. Park, I. Harjunkoski, M. Baldea, A time scale-bridging approach for integrating production scheduling and process control, Computers \& Chemical Engineering 79 (2015) 59 - 69, ISSN 0098-1354.

[14] C. R. Touretzky, M. Baldea, A hierarchical scheduling and control strategy for thermal energy storage systems, Energy and Buildings 110 (2016) 94 107, ISSN 0378-7788.

[15] M. A. Gutirrez-Limn, A. Flores-Tlacuahuac, I. E. Grossmann, A reactive optimization strategy for the simultaneous planning, scheduling and control of short-period continuous reactors, Computers \& Chemical Engineering 84 (2016) 507 - 515, ISSN 0098-1354.

[16] L. M. Ramrez-Elizondo, G. B. Paap, Scheduling and control framework for distribution-level systems containing multiple energy carrier systems: Theoretical approach and illustrative example, International Journal of Electrical Power \& Energy Systems 66 (2015) 194 - 215, ISSN 0142-0615.

[17] E. N. Pistikopoulos, N. A. Diangelakis, A. M. Manthanwar, Towards the integration of process design, control and scheduling: Are we getting closer?, in: J. K. H. Krist V. Gernaey, R. Gani (Eds.), 12th International Symposium on Process Systems Engineering and 25th European Symposium on Computer Aided Process Engineering, vol. 37 of Computer Aided Chemical Engineering, Elsevier, 41 - 48, http://dx.doi.org/10.1016/B978-0-44463578-5.50005-0, 2015.

[18] Y. Li, T. Yong, J. Cao, P. Ju, J. Yao, S. Yang, A consensus control strategy for dynamic power system look-ahead scheduling, Neurocomputing 168 (2015) 1085 - 1093, ISSN 0925-2312, http://dx.doi.org/10.1016/j.neucom.2015.05.015.

[19] M. Alipour, K. Zare, B. Mohammadi-Ivatloo, Short-term scheduling of combined heat and power generation units in the presence of demand response programs, Energy 71 (2014) 289 - 301, ISSN 0360-5442.

[20] F. Basrawi, T. K. Ibrahim, K. Habib, T. Yamada, Effect of operation strategies on the economic and environmental performance of a micro gas turbine trigeneration system in a tropical region, Energy 97 (2016) 262 272, ISSN 0360-5442. 
[21] F. Basrawi, T. Yamada, S. Obara, Economic and environmental based operation strategies of a hybrid photovoltaicmicrogas turbine trigeneration system, Applied Energy 121 (2014) 174 - 183, ISSN 0306-2619.

22] K. M. Powell, W. J. Cole, U. F. Ekarika, T. F. Edgar, Dynamic optimization of a campus cooling system with thermal storage, in: European Control Conference (ECC), 2013, 4077-4082, 2013.

[23] K. Kapoor, K. M. Powell, W. J. Cole, J. S. Kim, T. F. Edgar, Improved large-scale process cooling operation through energy optimization, Processes 1 (2013) 312-329.

[24] K. M. Powell, A. Sriprasad, W. J. Cole, T. F. Edgar, Heating, cooling, and electrical load forecasting for a large-scale district energy system, Energy 74 (2014) 877-885.

[25] K. M. Powell, W. J. Cole, U. F. Ekarika, T. F. Edgar, Optimal chiller loading in a district cooling system with thermal energy storage, Energy 50 (2013) 445-453.

[26] K. M. Powell, J. D. Hedengren, T. F. Edgar, Dynamic optimization of a solar thermal energy storage system over a 24 hour period using weather forecasts, in: American Control Conference (ACC), 2013, IEEE, 2946-2951, 2013.

[27] A. H. Nosrat, L. G. Swan, J. M. Pearce, Improved performance of hybrid photovoltaic-trigeneration systems over photovoltaic-cogen systems including effects of battery storage, Energy 49 (2013) 366 - 374, ISSN 0360-5442.

[28] K. M. Powell, Dynamic optimization of energy systems with thermal energy storage, Ph.D. thesis, The University of Texas at Austin, 2013.

[29] K. M. Powell, J. D. Hedengren, T. F. Edgar, Dynamic optimization of a hybrid solar thermal and fossil fuel system, Solar Energy 108 (2014) 210 218, ISSN 0038-092X.

[30] A. Martens, The energetic feasibility of CHP compared to the separate production of heat and power, Applied Thermal Engineering 18 (11)

a (1998) 935-946, ISSN 13594311, URL http://linkinghub.elsevier. com/retrieve/pii/S135943119800026X.

[31] K. M. Powell, J. S. Kim, W. J. Cole, K. Kapoor, J. Mojica, J. D. Hedengren, T. F. Edgar, Thermal energy storage to minimize cost and improve efficiency of a polygeneration district energy system in a real-time electricity market, Energy .

[32] J. Bisschop, AIMMS Optimization Modeling, Tech. Rep., Paragon Decision Technology, Bellevue, 2012. 
[33] M. A. Lozano, J. C. Ramos, L. M. Serra, Cost optimization of the design of CHCP (combined heat, cooling and power) systems under legal constraints, Energy 35 (2) (2010) 794-805, ISSN 03605442, URL http://linkinghub. elsevier.com/retrieve/pii/S0360544209003624

[34] L. M. Serra, M.-A. Lozano, J. Ramos, A. V. Ensinas, S. A. Nebra, Polygeneration and efficient use of natural resources, Energy 34 (5) (2009) 575-586, ISSN 03605442, URL http://linkinghub.elsevier.com/retrieve/pii/ S0360544208002004

[35] I. Kemp, Pinch Analysis and Process Integration, Butterworth-Heinemann, Oxford, second edn., 2007.

[36] A. Parkinson, R. Balling, J. Hedengren, Optimization Methods for Engineering Design, Brigham Young University, Provo, UT, 2013.

[37] G. Chicco, P. Mancarella, Distributed multi-generation: A comprehensive view, Renewable and Sustainable Energy Reviews 13 (3) (2009) 535-551, ISSN 13640321, URL http://linkinghub.elsevier.com/retrieve/pii/ S1364032107001578.

[38] C. Gamarra, J. M. Guerrero, Computational optimization techniques applied to microgrids planning: A review, Renewable and Sustainable Energy Reviews 48 (2015) 413 - 424, ISSN 1364-0321.

[39] A. Zidan, H. A. Gabbar, A. Eldessouky, Optimal planning of combined heat and power systems within microgrids, Energy 93, Part 1 (2015) 235 244, ISSN 0360-5442.

[40] P. Jochem, M. Schnfelder, W. Fichtner, An efficient two-stage algorithm for decentralized scheduling of micro-CHP units, European Journal of Operational Research 245 (3) (2015) 862 - 874, ISSN 0377-2217.

[41] P. P. Arcuri, G. Florio, P. Fragiacomo, A mixed integer programming model for optimal design of trigeneration in a hospital complex, Energy 32 (8) (2007) 1430-1447, ISSN 03605442.

[42] I. E. Grossmann, A structural optimization approach process synthesis II: Heat recovery networks 7 (6) (1983) 707-721.

[43] J. Aghaei, M.-I. Alizadeh, Multi-objective self-scheduling of CHP (combined heat and power)-based microgrids considering demand response programs and ESSs (energy storage systems), Energy 55 (2013) 1044 - 1054, ISSN 0360-5442, use an MILP approach to optimize dynamic operation of a CHP with energy storage over a 24-hour period.

[44] S. Mitra, L. Sun, I. E. Grossmann, Optimal scheduling of industrial combined heat and power plants under time-sensitive electricity prices, Energy 54 (2013) 194 - 211, ISSN 0360-5442. 
[45] J. S. Kim, T. F. Edgar, Optimal scheduling of combined heat and power plants using mixed-integer nonlinear programming, Energy 77 (2014) 675 - 690, ISSN 0360-5442.

[46] L. Biegler, V. Zavala, Large-scale nonlinear programming using IPOPT: An integrating framework for enterprise-wide dynamic optimization, Computers \& Chemical Engineering 33 (3) (2009) 575 - 582, ISSN 0098-1354, selected Papers from the 17th European Symposium on Computer Aided Process Engineering held in Bucharest, Romania, May 2007.

[47] L. Ricardez-Sandoval, P. Douglas, H. Budman, A methodology for the simultaneous design and control of large-scale systems under process parameter uncertainty, Computers \& Chemical Engineering 35 (2) (2011) 307-318,

(1) ISSN 00981354, URL/http://linkinghub.elsevier.com/retrieve/pii/ S0098135410001900

[48] S. B. Kim, A. A. Linninger, Integration of Design and Control for a large scale flowsheet, in: S. Pierucci, G. B. Ferraris (Eds.), 20th European Symposium on Computer Aided Process Engineering, vol. 28 of Computer Aided Chemical Engineering, Elsevier, 1279 - 1284, http://dx.doi.org/10.1016/S1570-7946(10)28214-7, 2010.

[49] L. Cheng, E. Subrahmanian, A. W. Westerberg, A comparison of optimal control and stochastic programming from a formulation and computation perspective, Computers \& Chemical Engineering 29 (1) (2004) 149-164,

n ISSN 00981354, URL http://linkinghub.elsevier.com/retrieve/pii/ S0098135404001826.

[50] A. G. Kagiannas, D. T. Askounis, J. Psarras, Power generation planning: a survey from monopoly to competition, International Journal of Electrical Power \& Energy Systems 26 (6) (2004) 413-421, ISSN 01420615, URL http://linkinghub.elsevier.com/retrieve/pii/S0142061503001315.

[51] Z. F. Liu, G. H. Huang, N. Li, A Dynamic Optimization Approach for Power Generation Planning under Uncertainty, Energy Sources, Part A: Recovery, Utilization, and Environmental Effects 30 (14-15) (2008) 14131431, ISSN 1556-7036.

[52] L. Tan, Y. Chen, A general framework for solving multi-objective optimization under uncertainty, 2009 IEEE 6th International Power Electronics and Motion Control Conference 3 (2009) 2432-2437, URL http://ieeexplore.ieee.org/lpdocs/epic03/wrapper.htm? arnumber $=5157810$.

[53] S. Nagl, D. Lindenberger, E. W. I. W. Paper, E. Economics, Optimization of power plant investments under uncertain renewable energy development paths-A multistage stochastic programming approach (12). 
[54] P. S. Reinelt, D. W. Keith, Carbon Capture Retrofits and the Cost of Regulatory Uncertainty, Energy Journal 28 (4) (2007) 101-128.

[55] S. Fuss, J. Szolgayova, M. Obersteiner, M. Gusti, Investment under market and climate policy uncertainty, Applied Energy 85 (8) (2008) 708-721, ISSN 03062619, URL http://linkinghub.elsevier.com/retrieve/pii/ S0306261908000287.

[56] A. R. Borges, C. H. Antunes, A fuzzy multiple objective decision support model for energy-economy planning, European Journal of Operational Research 145 (2003) 304-316.

[57] H. Tekiner, D. W. Coit, F. a. Felder, Multi-period multi-objective electricity generation expansion planning problem with Monte-Carlo simulation, Electric Power Systems Research 80 (12) (2010) 1394-1405,

a ISSN 03787796, URL http://linkinghub.elsevier.com/retrieve/pii/ S0378779610001276

[58] Y. Li, Y. Li, G. Huang, X. Chen, Energy and environmental systems planning under uncertainty-An inexact fuzzy-stochastic programming approach, Applied Energy 87 (10) (2010) 3189-3211, ISSN 03062619, URL http://linkinghub.elsevier.com/retrieve/pii/S0306261910000619.

[59] Y. Huang, C.-W. Chen, Y. Fan, Multistage optimization of the supply chains of biofuels, Transportation Research Part E: Logistics and Trans-

1 portation Review 46 (6) (2010) 820-830, ISSN 13665545, URL http: //linkinghub.elsevier.com/retrieve/pii/S1366554510000372.

[60] C. Gahm, F. Denz, M. Dirr, A. Tuma, Energy-efficient scheduling in manufacturing companies: A review and research framework, European Journal of Operational Research 248 (3) (2016) 744 - 757, ISSN 0377-2217.

[61] S. Qin, T. a. Badgwell, A survey of industrial model predictive control technology, Control Engineering Practice 11 (7) (2003) 733-764,

1. ISSN 09670661, URL http://linkinghub.elsevier.com/retrieve/pii/ S0967066102001867.

[62] D. E. Seborg, T. F. Edgar, D. A. Mellichamp, Process Dynamics and Control, John Wiley \& Sons, Hoboken, 2004.

[63] L. Ricardez-Sandoval, H. Budman, P. Douglas, Integration of design and control for chemical processes: A review of the literature and some recent results, Annual Reviews in Control 33 (2) (2009) 158-171,

口 ISSN 13675788, URL http://linkinghub.elsevier.com/retrieve/pii/ S1367578809000467.

[64] K. Subramanyan, U. M. Diwekar, A. Goyal, Multi-objective optimization for hybrid fuel cells power system under uncertainty, Journal of Power Sources 132 (1-2) (2004) 99-112, ISSN 03787753, URL 
http://linkinghub.elsevier.com/retrieve/pii/S0378775304000576 10.1016/j.jpowsour.2003.12.053.

[65] U.S. Department of Energy Intermountain Clean Energy Application Center, CHP Project Profiles, Tech. Rep., URL intermountaincleanenergy. org/profiles, 2011.

[66] J. D. Hedengren, R. A. Shishavan, K. M. Powell, T. F. Edgar, Nonlinear modeling, estimation and predictive control in APMonitor, Computers \& Chemical Engineering 70 (2014) 133 - 148.

[67] J. Renfro, A. Morshedi, O. Asbjornsen, Simultaneous optimization and solution of systems described by differential/algebraic equations, Computers and Chemical Engineering 11 (5) (1987) 503 - 517, ISSN 0098-1354.

[68] T. Binder, L. Blank, H. G. Bock, R. Bulirsch, Introduction to model based optimization of chemical processes on moving horizons, in: Online Optimization of Large Scale Systems, 295-339, 2001.

[69] L. T. Biegler, An overview of simultaneous strategies for dynamic optimization, Chemical Engineering and Processing: Process Intensification 46 (11) (2007) 1043-1053, ISSN 02552701, URL http://linkinghub.elsevier. com/retrieve/pii/S0255270107001122, 10.1016/j.cep.2006.06.021.

[70] W. J. Palm, System Dynamics, McGraw-Hill, 2 edn., 2010.

[71] R. Findeisen, F. Allgower, L. Biegler, Assessment and future directions of nonlinear model predictive control, Springer-Verlag, Berlin, 2007.

[72] S. M. Safdarnejad, J. D. Hedengren, N. R. Lewis, E. L. Haseltine, Initialization strategies for optimization of dynamic systems, Computers \& Chemical Engineering 78 (2015) 39 - 50, ISSN 0098-1354.

[73] B. J. Spivey, J. D. Hedengren, T. F. Edgar, Constrained nonlinear estimation for industrial process fouling, Industrial \& Engineering Chemistry Research 49 (17) (2010) 7824-7831.

[74] L. Sun, J. D. Hedengren, R. W. Beard, Optimal Trajectory Generation using Model Predictive Control for Aerially Towed Cable Systems, Journal

n of Guidance, Control, and Dynamics 37 (2) (2014) 525-539, URL http: //arc.aiaa.org/doi/abs/10.2514/1.60820

[75] R. Asgharzadeh Shishavan, C. Hubbell, H. Perez, J. Hedengren, D. Pixton, Combined Rate of Penetration and Pressure Regulation for Drilling Optimization by Use of High-Speed Telemetry, SPE Drilling \& Completion (SPE-170275-PA).

[76] N. R. Lewis, J. D. Hedengren, E. L. Haseltine, Hybrid Dynamic Optimization Methods for Systems Biology with Efficient Sensitivities, Pro-

n cesses 3 (3) (2015) 701, ISSN 2227-9717, URL http://www.mdpi.com/ $2227-9717 / 3 / 3 / 701$. 
[77] S. Safdarnejad, J. Gallacher, J. Hedengren, Dynamic Parameter Estimation and Optimization for Batch Distillation, Computers and Chemical Engineering 86 (2016) 18-32.

[78] A. Eaton, S. Safdarnejad, J. Hedengren, K. Moffat, C. Hubbell, D. Brower, A. Brower, Post-Installed Fiber Optic Pressure Sensors on Subsea Production Risers for Severe Slugging Control, in: ASME 34th International Conference on Ocean, Offshore, and Arctic Engineering (OMAE), 42196, St. John's, Newfoundland, Canada, 2015.

[79] J. D. Hedengren, A. N. Eaton, Overview of Estimation Methods for Industrial Dynamic Systems, Optimization and Engineering (2015) 1-24.

[80] J. L. Mojica, A Dynamic Optimization Framework with Model Predictive Control Elements for Long Term Planning of Capacity Investments in a District Energy System, Master's thesis, Brigham Young University, URL http://apm.byu.edu/prism/uploads/Members/Jose_Mojica_ thesis_2013.pdf, 2013.

[81] S. T. Incorporated, Solar Turbines, A Caterpillar Company, URL https: //mysolar.cat.com, 2015.

[82] R. Kurz, K. Brun, Degradation of gas turbine performance in natural gas service, Journal of Natural Gas Science and Engineering 1 (2009) 95 - 102.

[83] D. E. Seborg, Process dynamics and control, Wiley, Hoboken, NJ, 2 edn., 2004.

[84] A. Chittum, N. Kaufman, Challenges Facing Combined Heat and Power Today: A State-by-State Assessment, Tech. Rep., American Council for an Energy-Efficient Economy, Washington D.C., URL www .aceee.org, 2011.

[85] U.S. Energy Information Administration, Cost of Natural Gas Used in Manufacturing Sector Has Fallen, Tech. Rep., URL

nttp://www.eia.gov/consumption/manufacturing/reports/2010/ ng_cost/?src=Natural-f1, 2013.

[86] U.S. Energy Information Administration, Annual Energy Outlook 2015, Tech. Rep., U.S. Energy Information Administration, URL http://www. eia.gov/forecasts/aeo/pdf/0383(2015).pdf, 2015.

[87] D. P. Bertsekas, J. N. Tsitsiklis, Introduction to Probability, Athena Scientific, Nashua, 2nd edn., 2008.

[88] The Mathworks, Kernel Distribution, URL http://www.mathworks.com/ help/stats/kernel-distribution.html, 2015. 


\section{List of Figures}

1 Overview of district energy generation and distribution . . . . . . 37

$\begin{array}{llll}1224 & 2 & \text { Electricity and heating demand profiles for dynamic optimization. } 38\end{array}$

$3 \quad$ Forecasts of Natural Gas and Electricity Prices for Commercial

1226

$4 \quad$ CHP and boiler capacity investment plan over a 30 year horizon

1228

1230

5 Summer excess heat and heat production plan for six different

control objectives. . . . . . . . . . . . . . . . 41

6 Winter excess heat and heat production plan for six different

1232

control objectives. . . . . . . . . . . . . . . 42

7 Summer CHP electricity production and electricity import plan

1234

1236

8 Winter CHP electricity production and electricity import plan 9 for six different control objectives. . . . . . . . . . . . . . . . . . 44

1238

10 Summer excess heat and heat production plan for four different control objectives (cases removed for increased visibility). . . . . . 45

1242

-

1244 11 Different economic cases with 27 scenarios with a distribution of

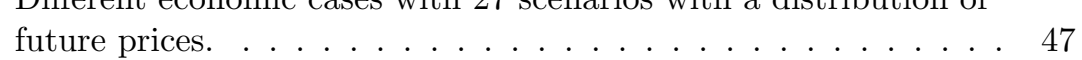

12 CHP and boiler capacities by economic scenario . . . . . . . . . 48

13 CHP and boiler total capacity. . . . . . . . . . . . . . 49

${ }_{1246}^{14}$ Frequency of Maximum Boiler and CHP Capacity . . . . . . . 50 


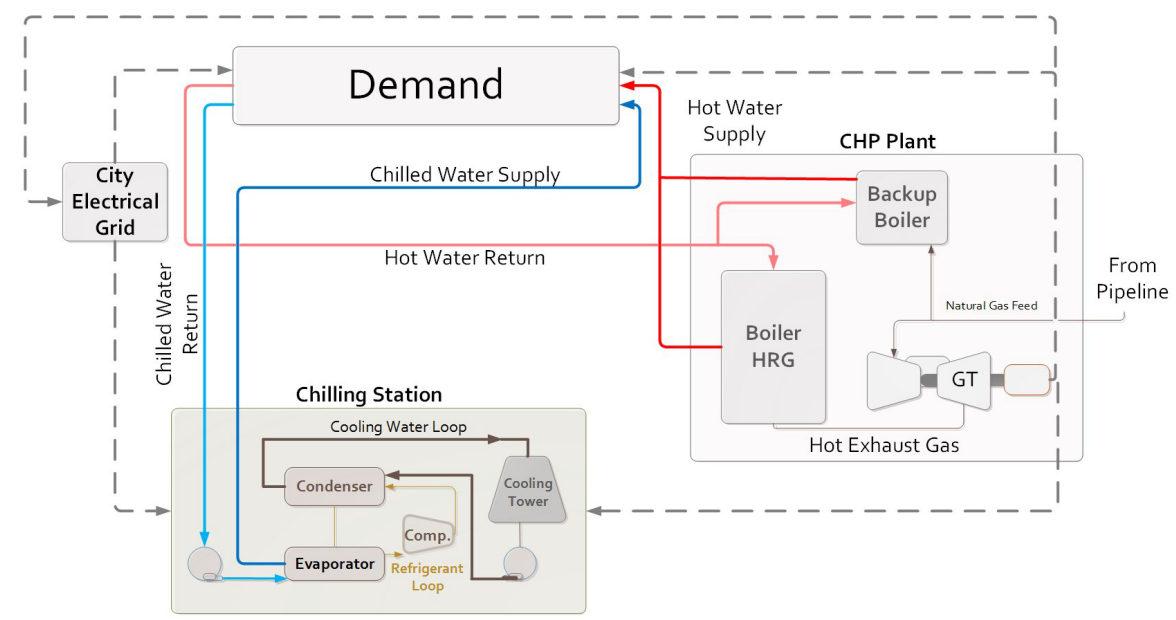

Figure 1: Overview of district energy generation and distribution 


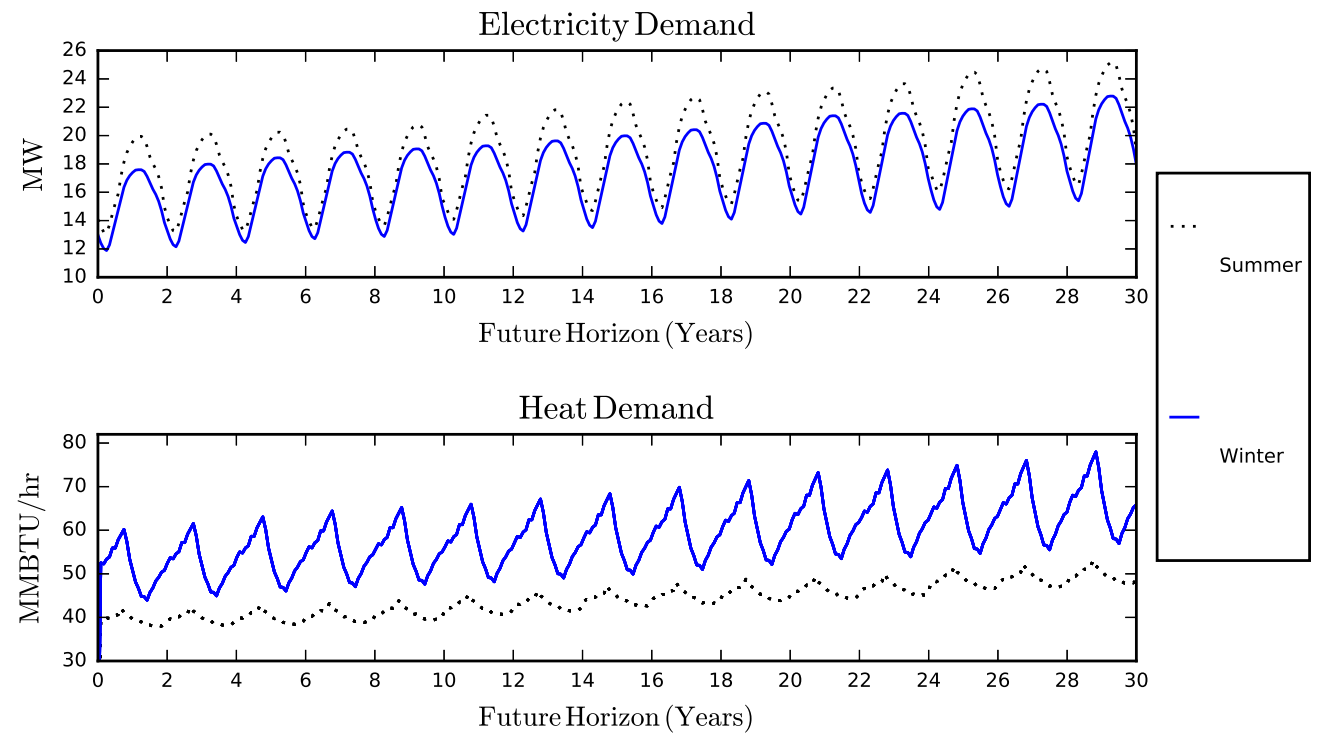

Figure 2: Electricity and heating demand profiles for dynamic optimization. 

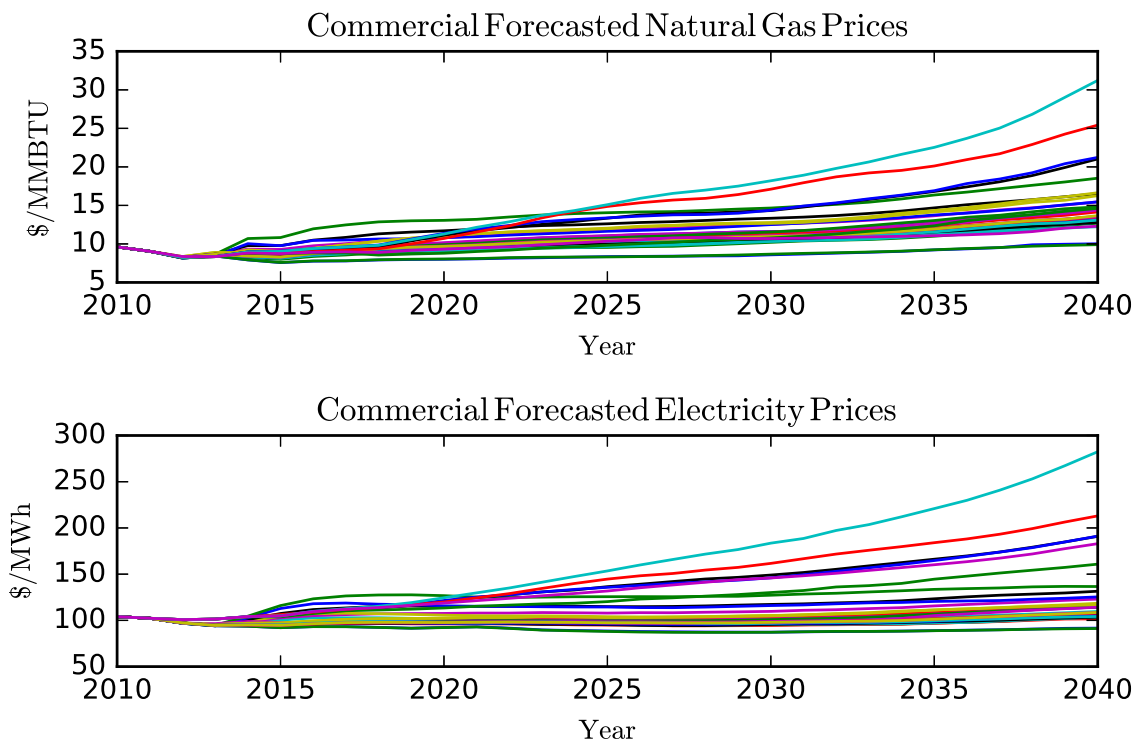

Figure 3: Forecasts of Natural Gas and Electricity Prices for Commercial End-Users for the Given Horizon 

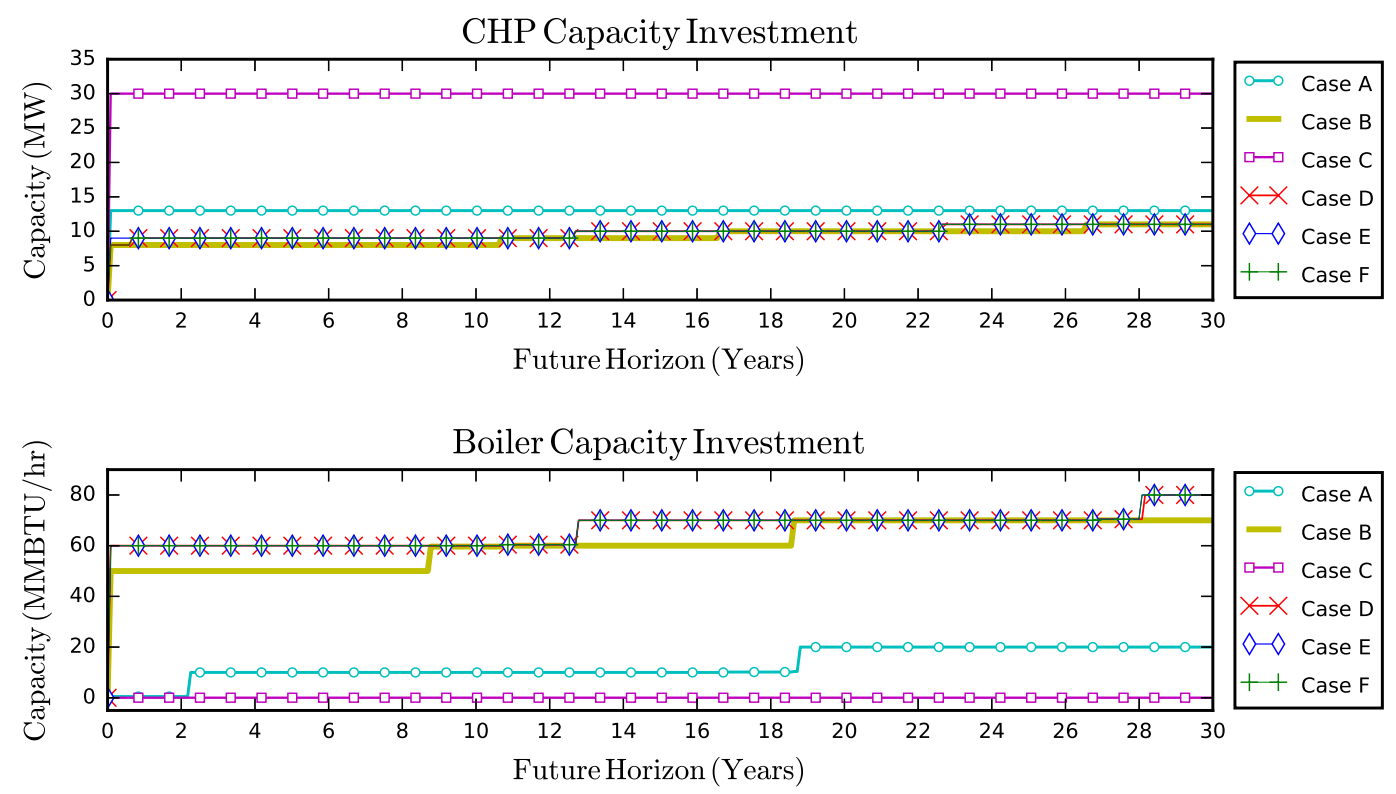

Figure 4: CHP and boiler capacity investment plan over a 30 year horizon based on six different control objectives. 
Summer Excess Heat
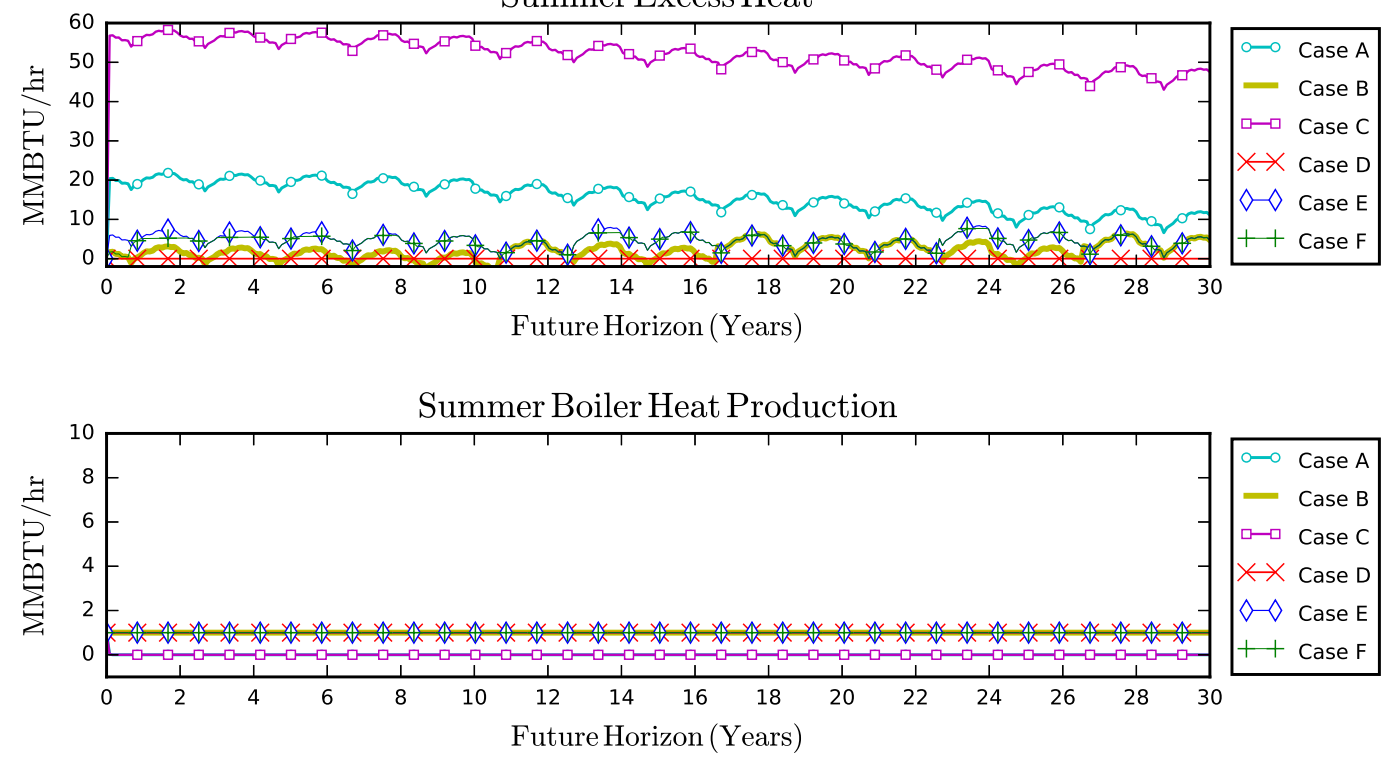

Figure 5: Summer excess heat and heat production plan for six different control objectives. 
Winter Excess Heat
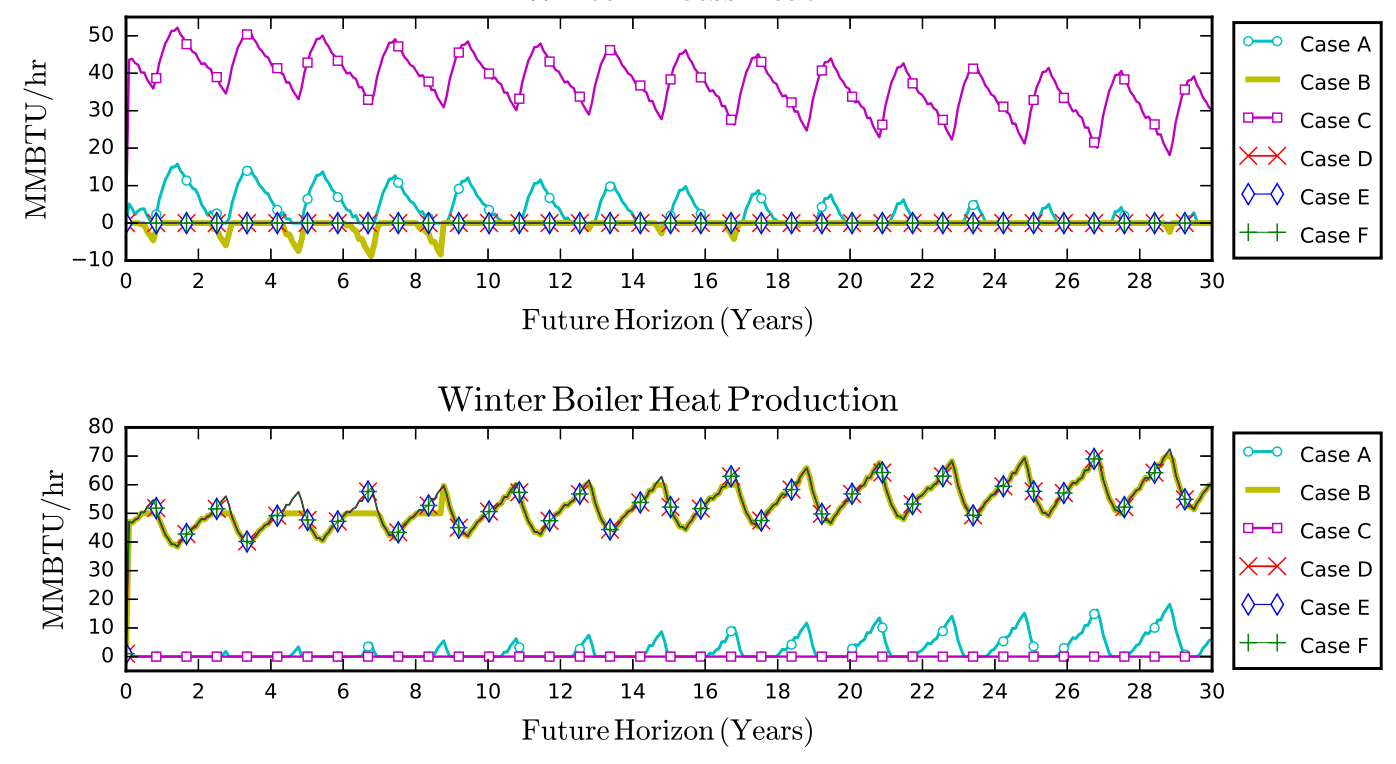

Figure 6: Winter excess heat and heat production plan for six different control objectives. 
Summer Electricity CHP Production

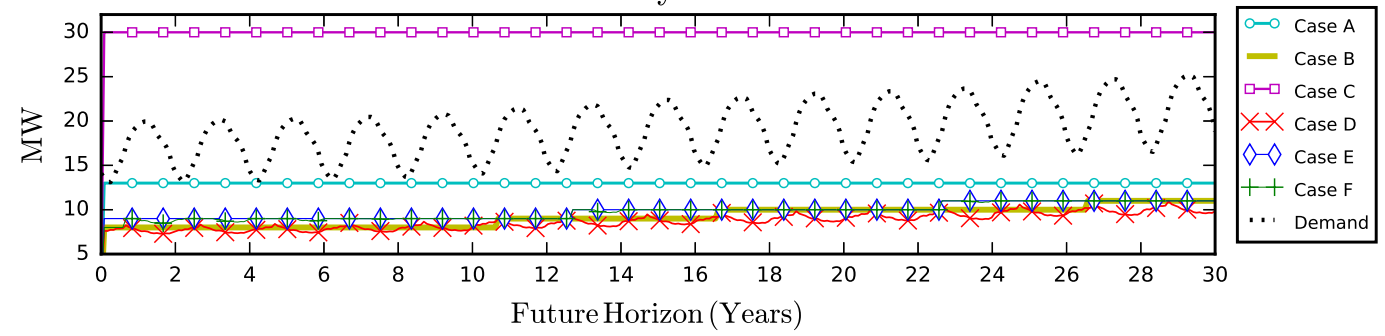

Summer Electricity Import

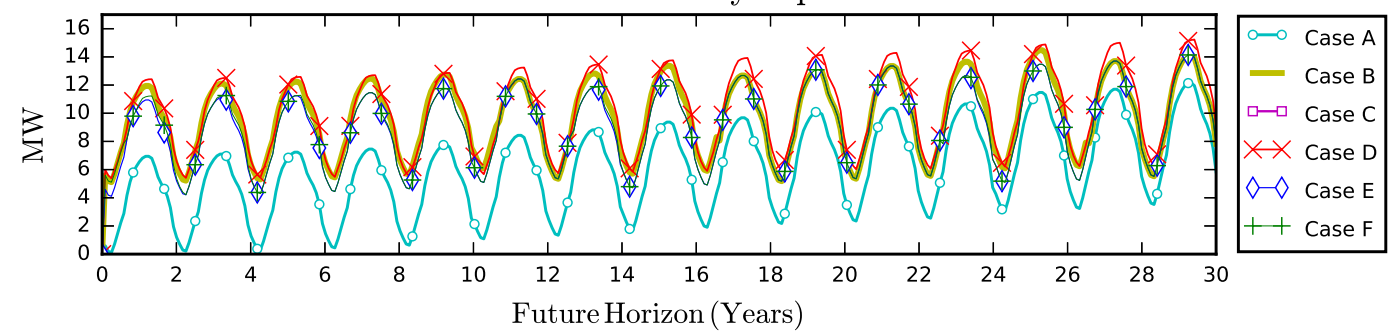

Figure 7: Summer CHP electricity production and electricity import plan for six different control objectives. 
Winter Electricity CHP Production
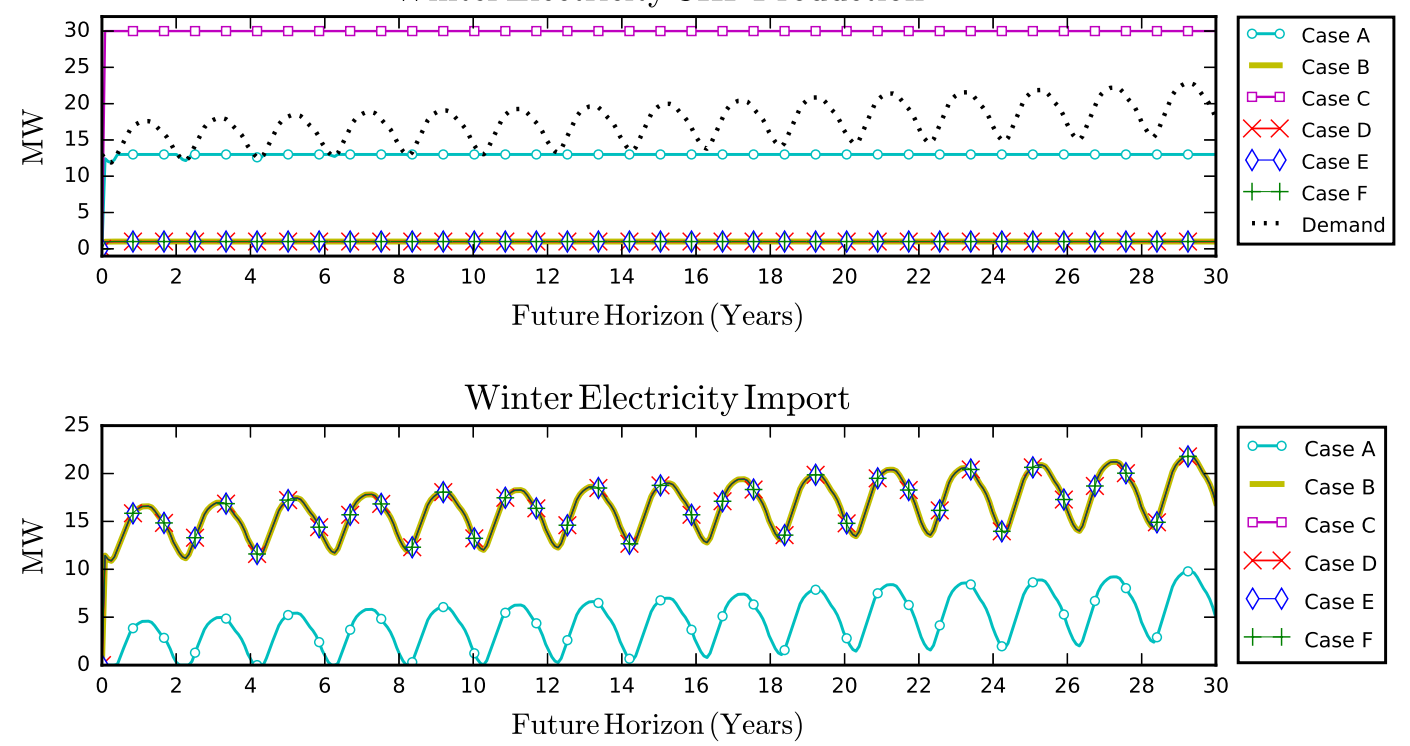

Figure 8: Winter CHP electricity production and electricity import plan for six different control objectives. 

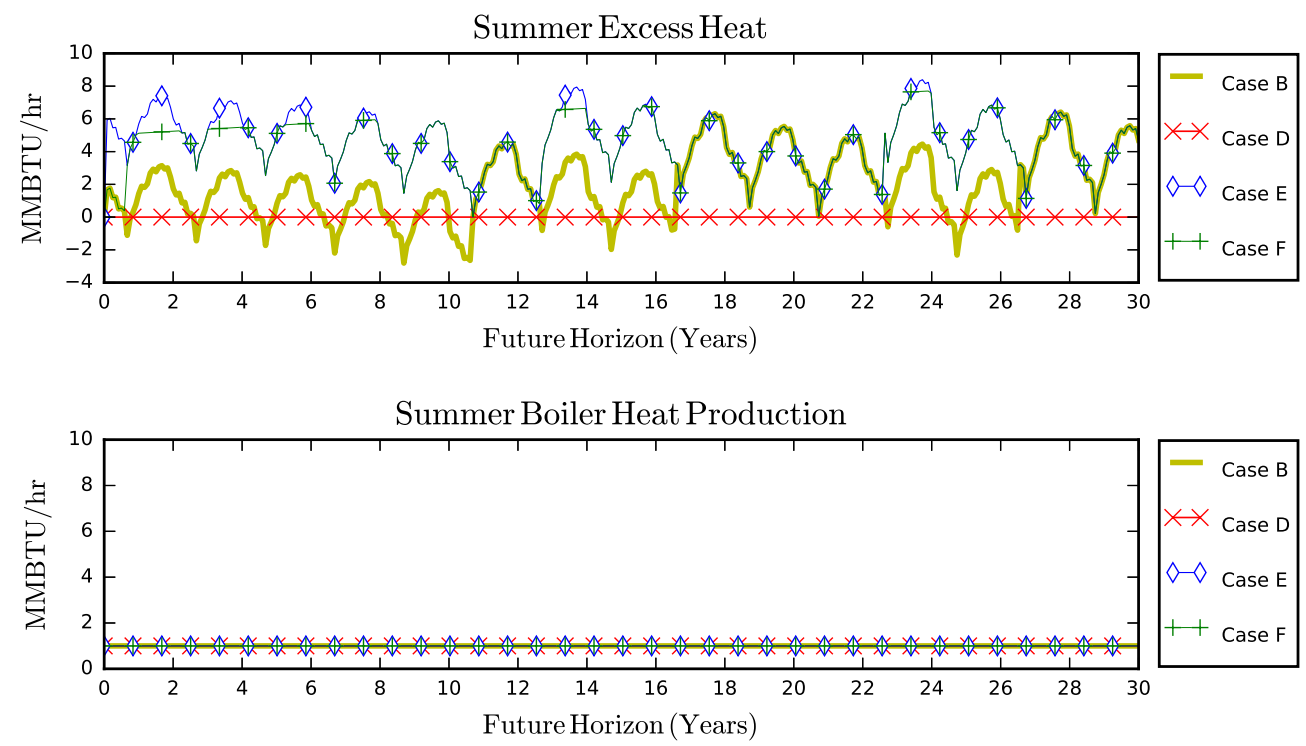

Figure 9: Summer excess heat and heat production plan for four different control objectives (cases removed for increased visibility). 

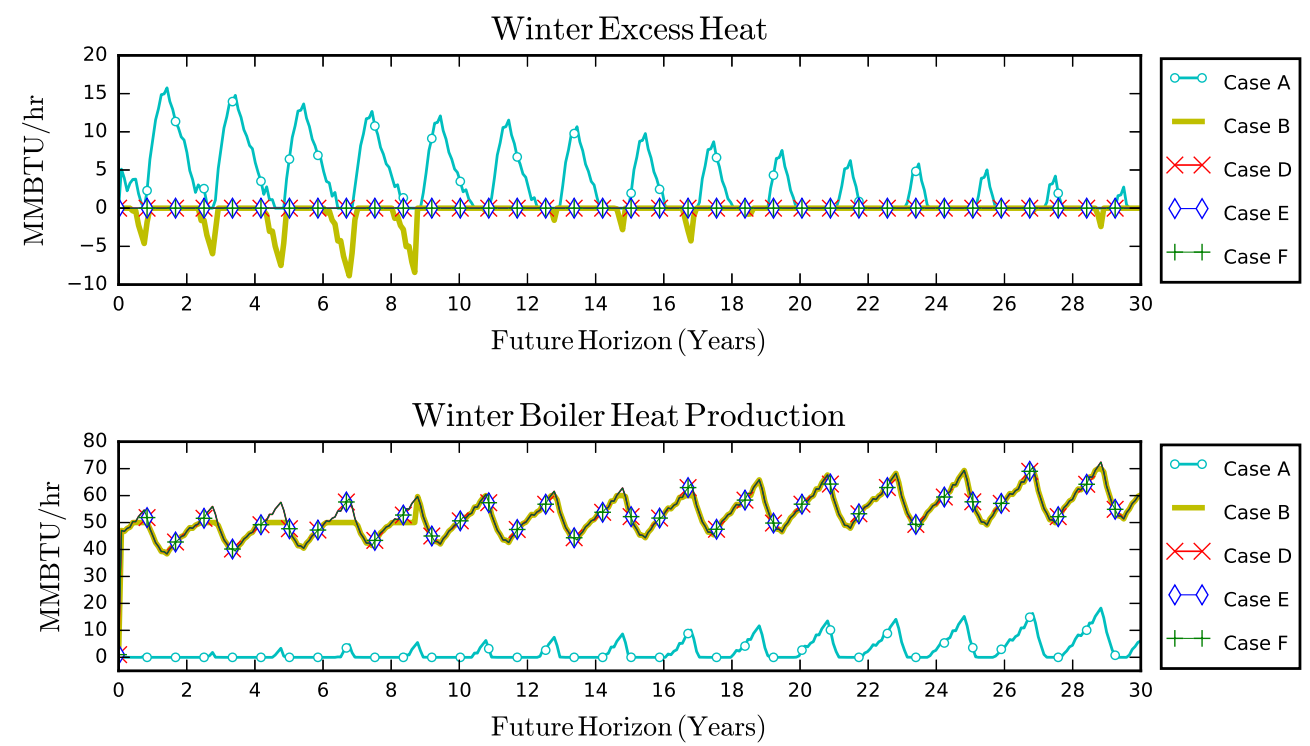

Figure 10: Winter excess heat and heat production plan for five different control objectives for the expected energy prices economic case (cases removed for increased visibility). 

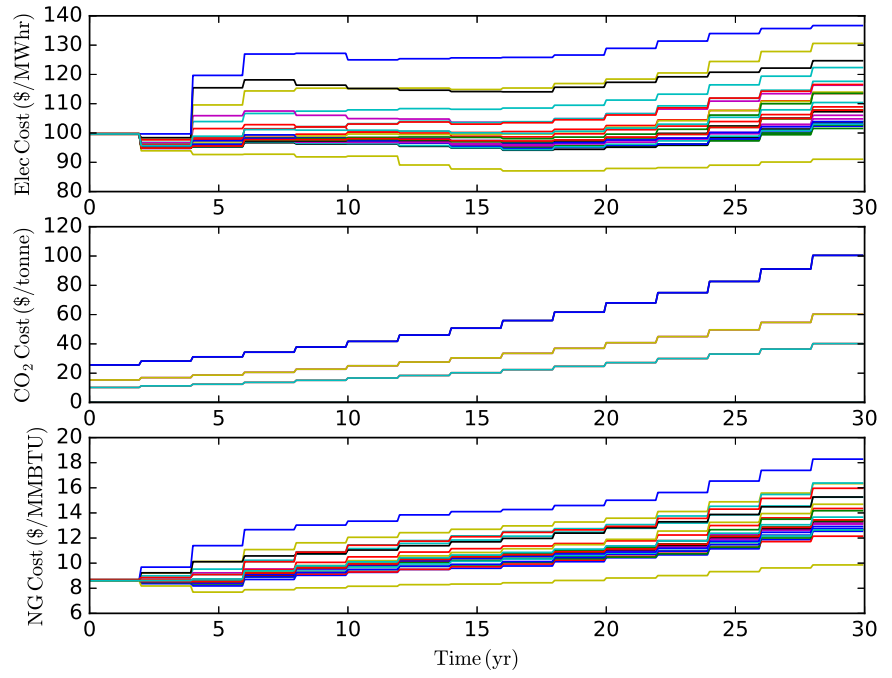

Figure 11: Different economic cases with 27 scenarios with a distribution of future prices. 

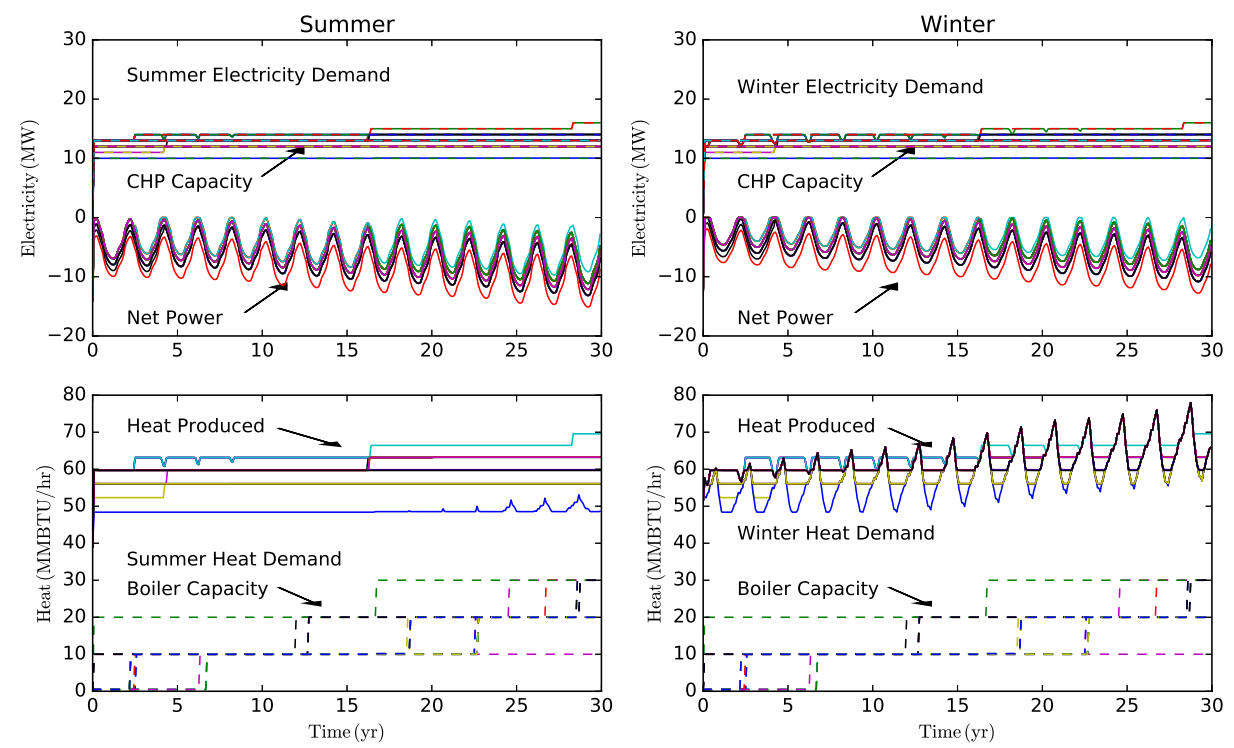

Figure 12: CHP and boiler capacities by economic scenario 


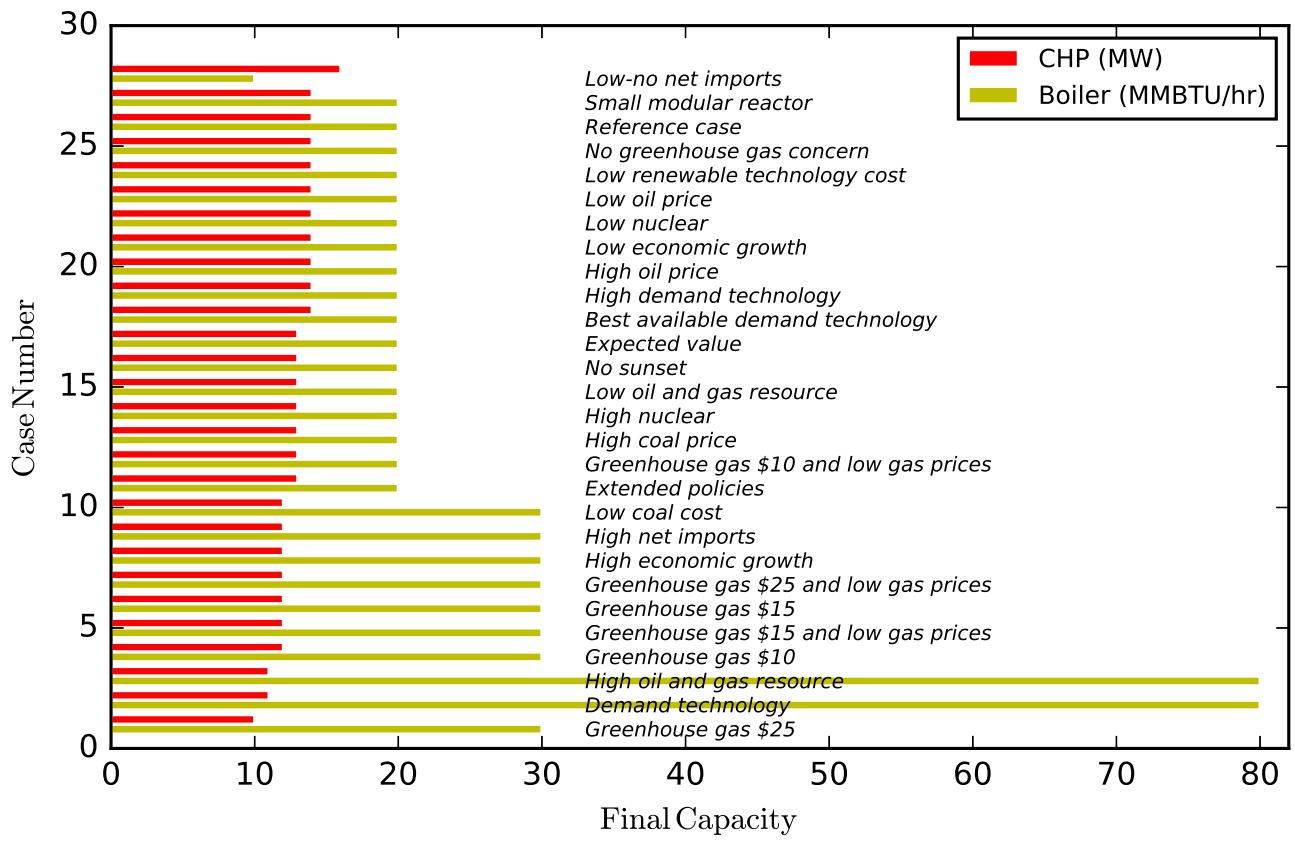

Figure 13: CHP and boiler total capacity. 

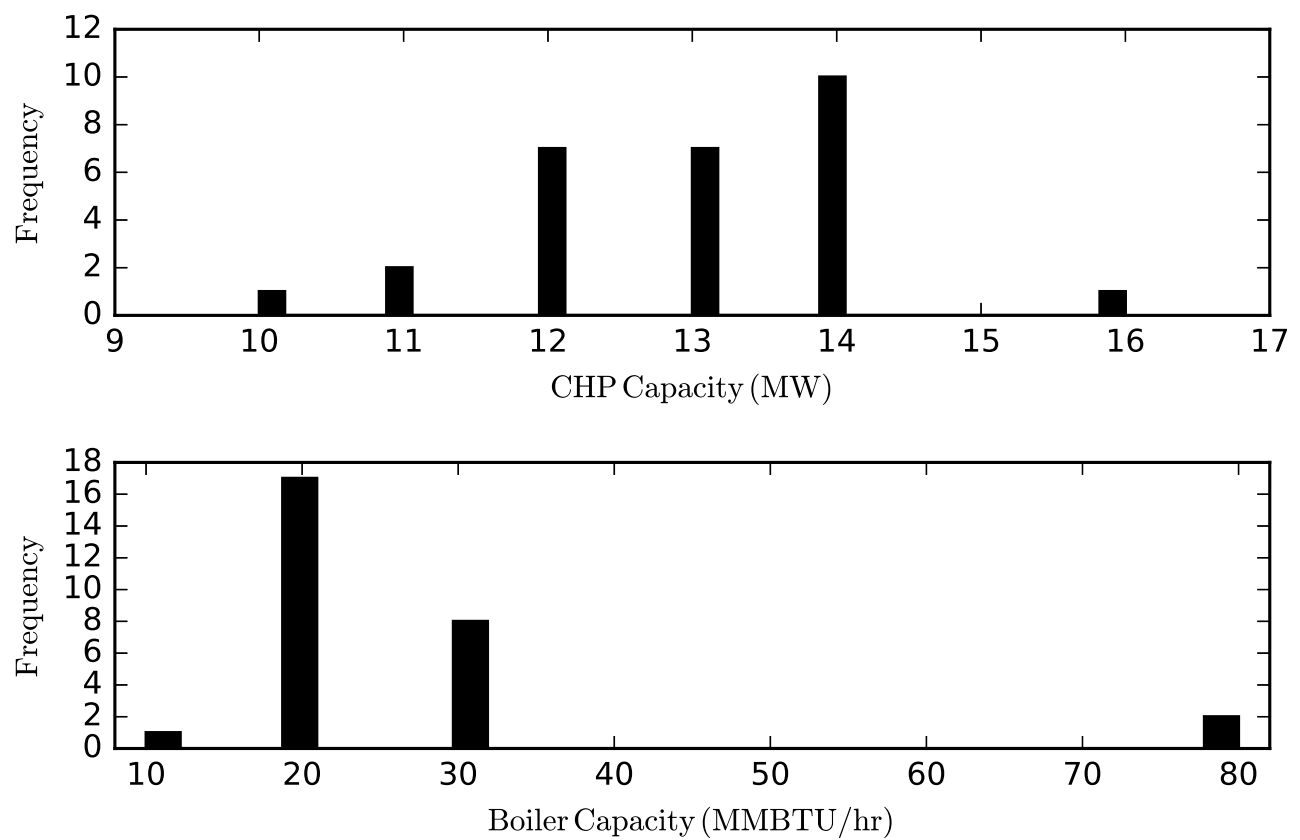

Figure 14: Frequency of Maximum Boiler and CHP Capacity 


\section{List of Tables}

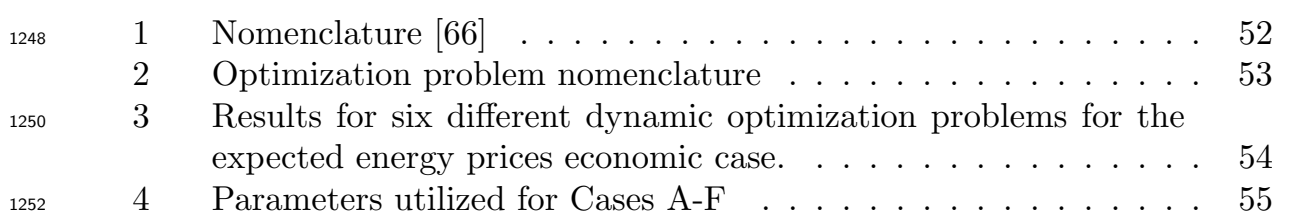


Table 1: Nomenclature 66

\begin{tabular}{|c|l|}
\hline$\Phi$ & objective function \\
\hline$y_{m}$ & model values $\left(y_{m, 0}, \ldots, y_{m, n}\right)^{T}$ \\
\hline$y_{t}, y_{t, h i}, y_{t, l o}$ & desired trajectory dead-band \\
\hline$w_{h i}, w_{l o}$ & penalty outside trajectory dead-band \\
\hline$c_{y}, c_{u}, c_{\Delta u}$ & cost of variables $y, u$, and $\Delta u$, respectively \\
\hline$u, x, d$ & inputs $(u)$, states $(x)$, parameters or disturbances $(d)$ \\
\hline$f, g, h$ & $\begin{array}{l}\text { equation residuals }(f), \text { output function }(g), \text { and inequality } \\
\text { constraints }(h)\end{array}$ \\
\hline$a, b$ & lower and upper limits \\
\hline$\tau_{c}$ & time constant of desired controlled variable response \\
\hline$e_{l o}, e_{h i}$ & slack variable below or above the trajectory dead-band \\
\hline$s p, s p_{l o}, s p_{h i}$ & $\begin{array}{l}\text { target,lower, and upper bounds to final set-point dead- } \\
\text { band }\end{array}$ \\
\hline
\end{tabular}


Table 2: Optimization problem nomenclature

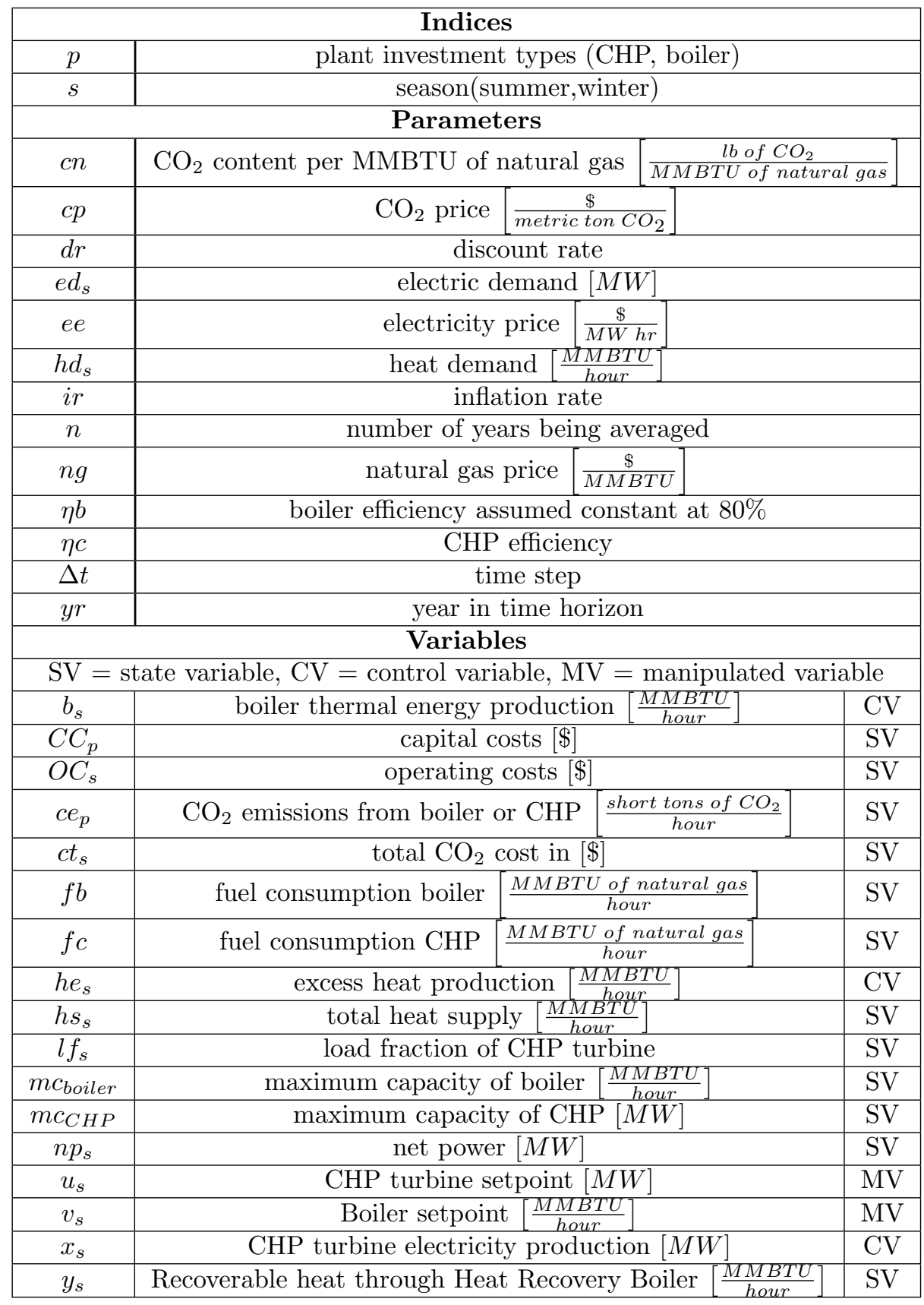


Table 3: Results for six different dynamic optimization problems for the expected energy prices economic case.

\begin{tabular}{|c|c|c|c|c|c|c|c|c|c|c|}
\hline 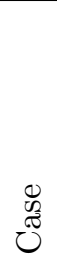 & 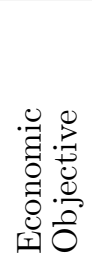 & 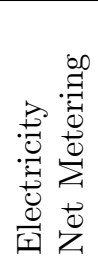 & 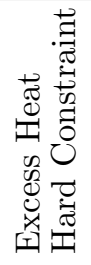 & 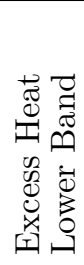 & 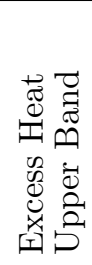 & 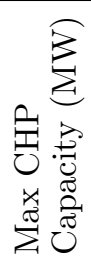 & 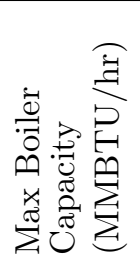 & 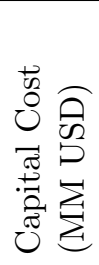 & 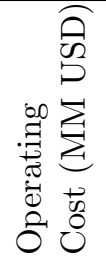 & 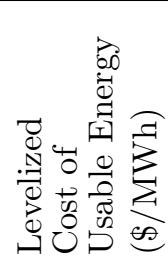 \\
\hline $\mathrm{A}$ & $\checkmark$ & $x$ & $\sqrt{ }$ & $x$ & $x$ & 13 & 20 & 16.2 & 230.8 & 23.99 \\
\hline B & $\checkmark$ & $x$ & $x$ & $\checkmark$ & $x$ & 11 & 70 & 15.4 & 288.3 & 26.42 \\
\hline $\mathrm{C}$ & $\sqrt{ }$ & $\checkmark$ & $\checkmark$ & $x$ & $x$ & 30 & 0 & 32.0 & 178.8 & 27.40 \\
\hline $\mathrm{D}$ & $\sqrt{ }$ & $x$ & $\sqrt{ }$ & $x$ & $\checkmark$ & 11 & 80 & 16.2 & 296.9 & 27.83 \\
\hline $\bar{E}$ & $\sqrt{ }$ & $x$ & $\sqrt{ }$ & $\sqrt{ }$ & $x$ & 11 & 80 & 16.1 & 290.5 & 27.13 \\
\hline $\mathrm{F}$ & $\checkmark$ & $x$ & $\checkmark$ & $\sqrt{ }$ & $\checkmark$ & 11 & 80 & 16.2 & 290.8 & 27.12 \\
\hline
\end{tabular}


Table 4: Parameters utilized for Cases A-F

\begin{tabular}{|c|c|c|c|c|}
\hline \multicolumn{5}{|c|}{ Parameter Values } \\
\hline Parameter & Value & \multicolumn{3}{|c|}{ Description } \\
\hline$d r$ & 0.06 & \multicolumn{3}{|c|}{ discount rate } \\
\hline$e d_{s}$ & See Figure 2$]^{k}$ & \multicolumn{3}{|c|}{ electric demand $[M W]$} \\
\hline$e e$ & See Figure $3^{k}$ & electricity price & $\frac{\$}{M W h r}$ & \\
\hline$h d_{s}$ & See Figure $2^{k}$ & \multicolumn{2}{|c|}{ heat demand $\left[\frac{M M B T U}{\text { hour }}\right]$} & \\
\hline$i r$ & 0.03 & \multicolumn{3}{|c|}{ inflation rate } \\
\hline$n$ & 2 & \multicolumn{3}{|c|}{ number of years being averaged } \\
\hline$n g$ & See Figure $3^{k}$ & natural gas price & $\frac{\$}{M M B T U}$ & \\
\hline$\eta b$ & $80 \%$ & \multicolumn{3}{|c|}{ boiler efficiency } \\
\hline$\eta c$ & See Eq. $10 \mathrm{~b}{ }^{k}$ & \multicolumn{3}{|c|}{ turbine efficiency } \\
\hline$\Delta t$ & 1 hour & \multicolumn{3}{|c|}{ time step } \\
\hline$\tau_{\text {boiler }}, \tau_{c h p}$ & $0.024 \mathrm{hr}, 0.024 \mathrm{hr}$ & \multicolumn{3}{|c|}{ time constants for boiler and CHP } \\
\hline \multicolumn{5}{|c|}{$\begin{array}{l}\text { * For parameters which change over time the same data or equation is utilized } \\
\text { for each case. A figure plotting the data points or an equation describing the } \\
\text { parameter is referenced in this table. }\end{array}$} \\
\hline
\end{tabular}

